Naciones Unidas

Asamblea General

Septuagésimo tercer período de sesiones

Tema 88 del programa

Solicitud de una opinión consultiva de la Corte Internacional de Justicia sobre las consecuencias jurídicas de la separación del archipiélago de Chagos de Mauricio en 1965

\title{
Opinión consultiva de la Corte Internacional de Justicia sobre las consecuencias jurídicas de la separación del archipiélago de Chagos de Mauricio en 1965
}

\section{Nota del Secretario General}

1. En la $88^{a}$ sesión plenaria de su septuagésimo primer período de sesiones, celebrada el 22 de junio de 2017, la Asamblea General, en su resolución 71/292, decidió, de conformidad con el Artículo 96 de la Carta de las Naciones Unidas, solicitar a la Corte Internacional de Justicia que, en cumplimiento del Artículo 65 de su Estatuto, emitiera una opinión consultiva sobre las siguientes cuestiones:

a) “Se completó con arreglo a derecho el proceso de descolonización de Mauricio cuando Mauricio obtuvo la independencia en 1968, 
después de la separación del archipiélago de Chagos de Mauricio y teniendo en cuenta el derecho internacional, incluidas las obligaciones recogidas en las resoluciones de la Asamblea General 1514 (XV), de 14 de diciembre de 1960, 2066 (XX), de 16 de diciembre de 1965, 2232 (XXI), de 20 de diciembre de 1966, y 2357 (XXII), de 19 de diciembre de 1967?”;

b) “¿Cuáles son las consecuencias en virtud del derecho internacional, incluidas las obligaciones reflejadas en las resoluciones mencionadas, que se derivan de que el Reino Unido de Gran Bretaña e Irlanda del Norte siga administrando el archipiélago de Chagos, entre otras cosas respecto a que Mauricio no pueda aplicar un programa para reasentar en el archipiélago de Chagos a sus nacionales, en particular los originarios del archipiélago de Chagos?".

2. El 25 de febrero de 2019, la Corte Internacional de Justicia emitió su opinión consultiva sobre la cuestión anterior.

3. El 5 de marzo de 2019 recibí la copia debidamente firmada y sellada de dicha opinión consultiva de la Corte.

4. Por la presente transmito a la Asamblea General la opinión consultiva emitida por la Corte Internacional de Justicia el 25 de febrero de 2019 en el asunto Consecuencias jurídicas de la separación del archipiélago de Chagos de Mauricio en 1965.

5. Las opiniones individuales, las opiniones separadas y las declaraciones anexas a la opinión consultiva se publicarán como adición a la presente nota. 
25 DE FEBRERO DE 2019 OPINIÓN CONSULTIVA

\section{CONSECUENCIAS JURÍDICAS DE LA SEPARACIÓN DEL ARCHIPIÉLAGO DE CHAGOS DE MAURICIO EN 1965}




\section{Índice}

Cronología de las actuaciones ................ 1 a $24 \quad 9$

I. Acontecimientos que llevaron a la aprobación de la solicitud de opinión consultiva ................ 25 a $53 \quad 16$

II. Competencia y facultad discrecional ............. 54 a $91 \quad 20$

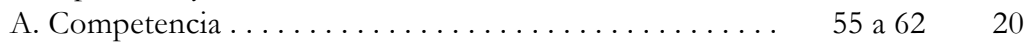

B. Facultad discrecional ................... 63 a $68 \quad 21$

1. Cuestión de si el procedimiento consultivo es adecuado para la determinación de cuestiones de hecho complejas y controvertidas ......................... 69 a $74 \quad 22$

2. Cuestión de si la respuesta de la Corte ayudaría a la Asamblea General en el desempeño de sus funciones .

3. Cuestión de si sería apropiado que la Corte volviera a examinar una cuestión presuntamente resuelta por el tribunal arbitral constituido con arreglo al anexo VII de la Convención de las Naciones Unidas sobre el Derecho del Mar en el Arbitraje sobre la zona marina protegida de Chagos... 4. Cuestión de si las cuestiones planteadas se refieren a una controversia pendiente entre dos Estados que no han dado su consentimiento para que sea resuelta por la Corte . . . . . . . . . . . . . . .

III. Contexto fáctico de la separación del archipiélago de Chagos de Mauricio . . . . . . . . . . . . . . . . .

A. Conversaciones entre el Reino Unido y los Estados Unidos sobre el archipiélago de Chagos ............ B. Conversaciones entre el Gobierno del Reino Unido y los representantes de la colonia de Mauricio sobre el archipiélago de Chagos ..................

C. Situación de los chagosianos . . . . . . . . . . . . . .

IV. Cuestiones planteadas a la Corte por la Asamblea General

A. Cuestión de si el proceso de descolonización de

Mauricio se completó con arreglo a derecho y teniendo en cuenta el derecho internacional (cuestión $a$ )) ........

1. Período de tiempo pertinente para determinar el derecho internacional aplicable . . . . . . . . . . . . . . 140 a 143

2. Derecho internacional aplicable.................
3. Funciones de la Asamblea General con respecto a la

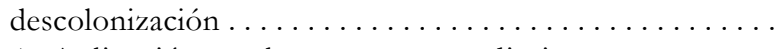
4. Aplicación en el presente procedimiento . . . . . . . B. Consecuencias en virtud del derecho internacional que se derivan de que el Reino Unido siga administrando el archipiélago de Chagos (cuestión b)) ..............

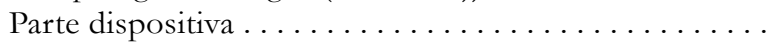




\title{
CORTE INTERNACIONAL DE JUSTICIA
}

\author{
AÑO 2019
}

25 de febrero

Lista general

Núm. 169

25 de febrero de 2019

\section{CONSECUENCIAS JURÍDICAS DE LA SEPARACIÓN DEL ARCHIPIÉLAGO DE CHAGOS DE MAURICIO EN 1965}

Acontecimientos que llevaron a la aprobación de la resolución 71/292 de la Asamblea General, en la que se solicita una opinión consultiva.

Ubicación geográfica de Mauricio en el océano Índico - Archipiélago de Chagos, inchida la isla de Diego García, administrado por el Reino Unido durante la colonización como una dependencia de Mauricio - Aprobación, el 14 de diciembre de 1960, de la Declaración sobre la Concesión de la Independencia a los Paises y Pueblos Coloniales (resolución 1514 (XV) de la Asamblea General) — Establecimiento del Comité Especial de Descolonización ("Comité de los Veinticuatro") para supervisar la aplicación de la resolución 1514 (XV) - Acuerdo de Lancaster House entre los representantes de la colonia de Mauricio y el Gobierno del Reino Unido en relación con la separación del archipiélago de Chagos de Mauricio - Creación del Territorio Británico del Océano Índico, incluido el archipiélago de Chagos - Acuerdo entre los Estados Unidos de América y el Reino Unido relativo a la disponibilidad del Territorio Británico del Océano Índico para fines de defensa - Aprobación por la Asamblea General de las resoluciones sobre la integridad territorial de los Territorios No Autónomos - Independencia de Mauricio - Expulsión forzosa de la población del archipiélago de Chagos - Solicitud de Mauricio de que se disuelva el Territorio Británico del Océano Índico y se le restituya el territorio - Creación de una zona marina protegida alrededor del archipiélago de Chagos por el Reino Unido — Impug- 
nación de la creación de una zona marina protegida por Mauricio ante un tribunal arbitral y decisión de este tribunal.

Competencia de la Corte para emitir la opinión consultiva solicitada.

Artículo 65, párrafo 1, del Estatuto - Artículo 96, párrafo 1, de la Carta - Competencia de la Asamblea General para solicitar opiniones consultivas Solicitud realizada de conformidad con la Carta — Las cuestiones sometidas a la Corte son de carácter jurídico.

Argumento de que no se ha formulado en términos precisos la cuestión respecto de la cual se hace la consulta — La falta de claridad de las cuestiones no puede privar a la Corte de su competencia - Argumentos examinados por la Corte al analizar las cuestiones planteadas por la Asamblea General.

La Corte tiene competencia para emitir la opinión consultiva solicitada.

$$
\text { ** }
$$

Facultad discrecional de la Corte para decidir si debe emitir una opinión.

Integridad de la función judicial de la Corte - Solo la existencia de "razones imperiosas" puede llevar a la Corte a negarse a ejercer su función judicial.

Argumento de que el procedimiento consultivo no es adecuado para la determinación de cuestiones de hecho complejas y controvertidas — Información suficiente sobre los hechos a disposición de la Corte.

Argumento de que la respuesta de la Corte no ayudaría a la Asamblea General en el desempeño de sus funciones — La determinación de la utilidad de la opinión corresponde al órgano solicitante.

Argumento de que una opinión consultiva de la Corte reabriría las cuestiones resueltas por un tribunal arbitral — Opinión emitida para la Asamblea General, no para los Estados - El principio de cosa juggada no impide la emisión de una opinión consultiva - Las cuestiones resueltas por el tribunal arbitral no son las mismas que las planteadas ante la Corte.

Argumento de que las cuestiones planteadas se refieren a una controversia territorial pendiente entre dos Estados que no han dado su consentimiento para que sea resuelta por la Corte - Las cuestiones se refieren a la descolonización de Mauricio - Papel activo que desempeña la Asamblea General con respecto a la descolonización - Las cuestiones planteadas en la solicitud se sitúan en el marco de referencia más amplio de 
la descolonización - La Corte no se ocupa de una controversia bilateral al emitir una opinión sobre cuestiones jurídicas respecto de las cuales ambos Estados han expresado supuestas opiniones divergentes — La emisión de la opinión solicitada no tiene por efecto soslayar el principio del consentimiento de un Estado al arreglo judicial de su controversia con otro Estado.

No bay razones imperiosas para que la Corte se niegue a emitir la opinión solicitada por la Asamblea General.

Contexto fáctico de la separación del archipiélago de Chagos de Mauricio y la expulsión de los chagosianos del archipiélago.

Conversaciones entre el Reino Unido y los Estados Unidos sobre el uso de ciertas islas de propiedad británica en el océano Índico para fines de defensa - Acuerdo entre las dos partes para el establecimiento de una base militar de los Estados Unidos en la isla de Diego García.

Conversaciones entre el Gobierno del Reino Unido y los representantes de la colonia de Mauricio con respecto al archipiélago de Chagos - Cuarta Conferencia Constitucional, celebrada en Londres en septiembre de 1965, con la participación de representantes de las dos partes - Acuerdo de Lancaster House - Acuerdo de principio de los representantes de la colonia de Mauricio para la separación del archipiélago de Chagos del territorio de Mauricio.

Situación de los chagosianos — Toda la población del archipiélago de Chagos fue expulsada a la fuerza del territorio entre 1967 y 1973 y se le probibió regresar Indemnización pagada por el Reino Unido a ciertos chagosianos - Diversos procesos iniciados por chagosianos ante los tribunales del Reino Unido, el Tribunal Europeo de Derechos Humanos y el Comité de Derechos Humanos - Recomendaciones del Comité en el sentido de que los chagosianos deberian poder ejercer su derecho a regresar a su territorio — En la actualidad los chagosianos están dispersos en varios países, entre ellos el Reino Unido, Mauricio y Seychelles — La legislación del Reino Unido y las decisiones judiciales de ese país no les permiten regresar al archipiélago.

Redacción de las cuestiones planteadas en la resolución 71/292 - Competencia de la Corte para aclarar las cuestiones que se le han planteado a fin de que emita una opinión consultiva - No es necesario reformular las cuestiones planteadas en este caso - No es necesario que la Corte interprete de manera restrictiva las cuestiones planteadas por la Asamblea General. 
Cuestión de si el proceso de descolonización de Mauricio se completó con arreglo a derecho y teniendo en cuenta el derecho internacional.

Periodo pertinente y derecho aplicable.

Elperiodo pertinente se sitúa entre la separación del archipiélago de Chagos en 1965 y la independencia de Mauricio en 1968 - Evolución del derecho a la libre determinación - El derecho a la libre determinación tiene un ámbito de aplicación amplio como derecho bumano fundamental — En el presente procedimiento, la Corte se limita a analizar ese derecho en el contexto de la descolonización - Derecho a la libre determinación consagrado en la Carta y reafirmado en resoluciones posteriores de la Asamblea General — La resolución 1514 (XV) constituye un momento decisivo en la consolidación de la práctica de los Estados en materia de descolonización - Carácter declaratorio de la resolución 1514 (XV) en lo relativo al derecho a la libre determinación como norma consuetudinaria - La resolución 1514 (XV) dispone que todo intento de alterar la unidad nacional y la integridad territorial de un país e s incompatible con los propósitos y principios de la Carta - Reafirmación del derecho de todos los pueblos a la libre determinación en el Pacto Internacional de Derechos Civiles y Politicos y el Pacto de Derechos Económicos, Sociales y Culturales - Derecho a la libre determinación reiterado en la Declaración sobre los Principios de Derecho Internacional referentes a las Relaciones de Amistad y a la Cooperación entre los Estados de conformidad con la Carta de las Naciones Unidas - Medios para hacer efectivo el derecho a la libre determinación en un Territorio No Autónomo establecidos en la resolución 1541 (XV) - El ejercicio de la libre determinación debe ser la expresión libre y auténtica de la voluntad del pueblo de que se trate _ El derecho a la libre determinación en virtud del derecho internacional consuetudinario no impone un mecanismo específico para su aplicación en todos los casos - Derecho a la libre determinación de un pueblo definido por referencia a la totalidad de un Territorio No Autónomo - Carácter consuetudinario del derecho a la integridad territorial de un Territorio No Autónomo como corolario del derecho a la libre determinaciónIncompatibilidad con el derecho a la libre determinación de cualquier separación por la Potencia administradora de una parte de un Territorio No Autónomo, a menos que dicha separación se base en la voluntad auténtica y libremente expresada del pueblo del Territorio en cuestión.

El derecho a la libre determinación, como norma consuetudinaria, constituye el derecho internacional aplicable durante el periodo pertinente.

Funciones de la Asamblea General con respecto a la descolonización. 
Función esencial de la Asamblea General con respecto a la descolonización Seguimiento de los medios a través de los cuales se expresa la voluntad libre y auténtica del pueblo de un Territorio No Autónomo - La Asamblea General ha exhortado sistemáticamente a las Potencias administradoras a que respeten la integridad territorial de los Territorios No Autónomos.

Examen de las circunstancias relativas a la separación del archipiélago de Chagos y su conformidad con el derecho internacional aplicable.

Acuerdo de principio del Consejo de Ministros de Mauricio para la separación del archipiélago de Chagos cuando la colonia de Mauricio se encontraba bajo la autoridad del Reino Unido, su Potencia administradora - Ese acuerdo no es un acuerdo internacional — Inexistencia de una expresión libre y auténtica de la voluntad del pueblo — Ilicitud de la separación del archipiélago de Chagos y de su incorporación a una nueva colonia, conocida como Territorio Británico del Océano Índico.

Proceso de descolonización de Mauricio no completado con arreglo a derecho cuando Mauricio accedió a la independencia en 1968.

Consecuencias en virtud del derecho internacional que se derivan de que el Reino Unido siga administrando el archipiélago de Chagos.

Descolonización de Mauricio no llevada a cabo de manera compatible con el derecho de los pueblos a la libre determinación - El hecho de que el Reino Unido siga administrando el archipiélago de Chagos constituye un hecho ilicito que entraña la responsabilidad internacional de ese Estado — Carácter continuo del hecho ilícito

- El Reino Unido tiene la obligación de poner fin a su administración del archipiélago de Chagos con la mayor rapidez.posible - Corresponde a la Asamblea General determinar las modalidades para completar el proceso de descolonización de Mauricio.

Obligación de todos los Estados Miembros de cooperar con las Naciones Unidas a fin de poner en práctica las modalidades para completar el proceso de descolonización de Mauricio — El reasentamiento en el archipiélago de Chagos de los nacionales de Mauricio, en particular los originarios del archipiélago de Chagos, es una cuestión relativa a la protección de los derechos humanos de las personas afectadas - La Asamblea General debería abordar ese tema durante la conclusión del proceso de descolonización de Mauricio. 


\section{OPINIÓN CONSULTIVA}

Presentes: Presidente YUSUF; Vicepresidenta XUE; Magistrados TOMKA, ABRAHAM, BENNOUNA, CANÇADO TRINDADE, DONOGHUE, GAJA, SEBUTINDE, BHANDARI, ROBINSON, GEVORGIAN, SALAM, IWASAWA; Secretario COUVREUR.

Sobre las consecuencias jurídicas de la separación del archipiélago de Chagos de Mauricio en 1965,

LA CORTE,

compuesta por los miembros antes mencionados,

emite la siguiente opinión consultiva:

1. Las cuestiones sobre las cuales se ha solicitado la opinión consultiva de la Corte se enuncian en la resolución 71/292, aprobada por la Asamblea General de las Naciones Unidas (en lo sucesivo, la "Asamblea General") el 22 de junio de 2017. Por carta de fecha 23 de junio de 2017, recibida en la Secretaría de la Corte el 28 de junio de 2017, el Secretario General de las Naciones Unidas comunicó oficialmente a la Corte la decisión adoptada por la Asamblea General de plantearle esas cuestiones para que emitiera una opinión consultiva. A la carta se adjuntaron copias certificadas del texto en francés e inglés de la resolución. La resolución reza lo siguiente:

\section{"La Asamblea General,}

Reafirmando que todos los pueblos tienen un derecho inalienable al ejercicio de su soberanía y a la integridad de su territorio nacional,

Recordando la Declaración sobre la Concesión de la Independencia a los Países y Pueblos Coloniales, que figura en su resolución 1514 (XV), de 14 de diciembre de 1960, y en particular su párrafo 6, en el que se afirma que todo intento encaminado a quebrantar total o parcialmente la unidad nacional y la integridad territorial de un país es incompatible con los propósitos y principios de la Carta de las Naciones Unidas,

Recordando también su resolución 2066 (XX), de 16 de diciembre de 1965, en la que invitó al Gobierno del Reino Unido de 
Gran Bretaña e Irlanda del Norte a adoptar medidas eficaces para dar cumplimiento inmediato y completo a la resolución 1514 (XV) y a no adoptar ninguna medida que pudiera desmembrar el Territorio de la Isla Mauricio y violar su integridad territorial, y sus resoluciones 2232 (XXI), de 20 de diciembre de 1966, y 2357 (XXII), de 19 de diciembre de 1967,

Teniendo presente su resolución 65/118, de 10 de diciembre de 2010, relativa al cincuentenario de la Declaración sobre la Concesión de la Independencia a los Países y Pueblos Coloniales, reiterando su opinión de que corresponde a las Naciones Unidas seguir desempeñando un papel activo en el proceso de descolonización, y haciendo notar que el proceso de descolonización aún no ha concluido,

Recordando su resolución 65/119, de 10 de diciembre de 2010, en la que declaró el período 2011-2020 Tercer Decenio Internacional para la Eliminación del Colonialismo, y su resolución 71/122, de 6 de diciembre de 2016, en la que pidió que se aplicara de forma inmediata y plena la Declaración sobre la Concesión de la Independencia a los Países y Pueblos Coloniales,

Haciendo notar las resoluciones sobre el archipiélago de Chagos aprobadas por la Organización de la Unidad Africana y la Unión Africana desde 1980, más recientemente en el $28^{\circ}$ período ordinario de sesiones de la Asamblea de la Unión, celebrado en Addis Abeba los días 30 y 31 de enero de 2017, y las resoluciones sobre el archipiélago de Chagos aprobadas por el Movimiento de los Países No Alineados desde 1983, más recientemente en la $17^{a}$ Conferencia de Jefes de Estado o de Gobierno de los Países No Alineados, celebrada en la Isla Margarita (República Bolivariana de Venezuela) del 13 al 18 de septiembre de 2016, y en particular la profunda preocupación expresada en ellas por la expulsión forzosa de todos los habitantes del archipiélago de Chagos por el Reino Unido de Gran Bretaña e Irlanda del Norte,

Haciendo notar también su decisión de 16 de septiembre de 2016 de incluir en el programa de su septuagésimo primer período de sesiones el tema titulado 'Solicitud de una opinión consultiva de la Corte Internacional de Justicia sobre las consecuencias jurídicas de la separación del archipiélago de Chagos de Mauricio 
en 1965', en el entendimiento de que el tema no se examinaría antes de junio de 2017,

Decide, de conformidad con el Artículo 96 de la Carta de las Naciones Unidas, solicitar a la Corte Internacional de Justicia que, en cumplimiento del Artículo 65 del Estatuto de la Corte, emita una opinión consultiva sobre las siguientes cuestiones:

a) ¿'Se completó con arreglo a derecho el proceso de descolonización de Mauricio cuando Mauricio obtuvo la independencia en 1968, después de la separación del archipiélago de Chagos de Mauricio y teniendo en cuenta el derecho internacional, incluidas las obligaciones recogidas en las resoluciones de la Asamblea General 1514 (XV), de 14 de diciembre de 1960, 2066 (XX), de 16 de diciembre de 1965, 2232 (XXI), de 20 de diciembre de 1966, y 2357 (XXII), de 19 de diciembre de 1967?';

b) ¿Cuáles son las consecuencias en virtud del derecho internacional, incluidas las obligaciones reflejadas en las resoluciones mencionadas, que se derivan de que el Reino Unido de Gran Bretaña e Irlanda del Norte siga administrando el archipiélago de Chagos, entre otras cosas respecto a que Mauricio no pueda aplicar un programa para reasentar en el archipiélago de Chagos a sus nacionales, en particular los originarios del archipiélago de Chagos?'."

2. El Secretario de la Corte, mediante cartas de fecha 28 de junio de 2017, notificó la solicitud de opinión consultiva a todos los Estados con derecho a comparecer ante la Corte, de conformidad con el Artículo 66, párrafo 1, del Estatuto.

3. Mediante providencia de 14 de julio de 2017, la Corte decidió, de conformidad con lo dispuesto en el Artículo 66, párrafo 2, del Estatuto, que las Naciones Unidas y sus Estados Miembros podían suministrar información sobre las cuestiones sometidas a la Corte para que emitiera una opinión consultiva y fijó el 30 de enero de 2018 como plazo para presentar exposiciones escritas sobre esas cuestiones y el 16 de abril de 2018 como plazo para que los Estados y organizaciones que hubieran presentado una exposición escrita pudieran formular observaciones por escrito sobre las exposiciones escritas de los demás. 
4. El Secretario de la Corte, mediante cartas de fecha 18 de julio de 2017, informó a las Naciones Unidas y sus Estados Miembros de las decisiones de la Corte y les transmitió una copia de la providencia.

5. De conformidad con el Artículo 65, párrafo 2, del Estatuto, el Secretario General de las Naciones Unidas, por medio de una carta de 30 de noviembre de 2017 del Asesor Jurídico de las Naciones Unidas, transmitió a la Corte un legajo de documentos que podrían arrojar luz sobre las cuestiones formuladas por la Asamblea General, que fue recibido en la Secretaría de la Corte el 4 de diciembre de 2017.

6. Mediante carta de 10 de enero de 2018, recibida en la Secretaría de la Corte el mismo día, la Asesora Jurídica de la Unión Africana pedía, en primer lugar, que se autorizara a la Unión Africana a suministrar información, por escrito y oralmente, sobre las cuestiones sometidas a la Corte para que emitiera una opinión consultiva y, en segundo lugar, que se le concediera una prórroga de un mes para presentar su exposición escrita.

7. Mediante providencia de 17 de enero de 2018, la Corte decidió que la Unión Africana podía estar en condiciones de suministrar información sobre las cuestiones sometidas a la Corte para que emitiera una opinión consultiva y que podría hacerlo dentro de los plazos fijados por la Corte. En la misma providencia, la Corte decidió además prorrogar hasta el 1 de marzo de 2018 el plazo para presentar a la Corte todas las exposiciones escritas, de conformidad con lo dispuesto en el Artículo 66, párrafo 2, de su Estatuto, y prorrogar hasta el 15 de mayo de 2018 el plazo para que los Estados y organizaciones que hubieran presentado una exposición escrita pudieran formular observaciones por escrito, de conformidad con lo dispuesto en el Artículo 66, párrafo 4, del Estatuto.

8. El Secretario de la Corte, mediante cartas de fecha 17 de enero de 2018, informó a las Naciones Unidas y sus Estados Miembros, así como a la Unión Africana, de las decisiones de la Corte y les transmitió una copia de la providencia.

9. Dentro del plazo prorrogado fijado por la Corte en su providencia de 17 de enero de 2018 se recibieron en la Secretaría de la Corte exposiciones escritas presentadas (por orden de recepción) por Belice, Alemania, Chipre, Liechtenstein, los Países Bajos, el Reino Unido de Gran Bretaña e Irlanda del Norte, Serbia, Francia, Israel, la Federación de Rusia, 
los Estados Unidos de América, Seychelles, Austr alia, la India, Chile, el Brasil, la República de Corea, Madagascar, China, Djibouti, Mauricio, Nicaragua, la Unión Africana, Guatemala, la Argentina, Lesotho, Cuba, Viet Nam, Sudáfrica, las Islas Marshall y Namibia.

10. En una comunicación de fecha 5 de marzo de 2018, la Secretaría de la Corte informó a los Estados que habían presentado exposiciones escritas, así como a la Unión Africana, de la lista de participantes que habían presentado exposiciones escritas en el procedimiento y explicó que había puesto en marcha un sitio web específico desde el que podían descargarse esas exposiciones. En la misma comunicación, la Secretaría de la Corte también informó a esos Estados y a la Unión Africana de que la Corte había decidido celebrar audiencias que comenzarían el 3 de septiembre de 2018.

11. El 14 de marzo de 2018, la Corte decidió, a título excepcional, autorizar la presentación fuera de plazo de la exposición escrita de la República del Níger.

12. El mismo día, el Secretario de la Corte informó a las Naciones Unidas y a sus Estados Miembros que no habían presentado exposiciones escritas de que se habían presentado exposiciones escritas a la Secretaría de la Corte. En la misma comunicación, el Secretario indicó también que la Corte había decidido celebrar audiencias que comenzarían el 3 de septiembre de 2018, durante las cuales las Naciones Unidas y sus Estados Miembros podrían presentar exposiciones y observaciones orales, con independencia de que hubieran o no presentado exposiciones escritas y, en su caso, observaciones por escrito.

13. El 15 de marzo de 2018, el Secretario de la Corte transmitió un conjunto completo de las exposiciones escritas recibidas en la Secretaría de la Corte a todos los Estados que habían presentado exposiciones escritas, así como a la Unión Africana.

14. Mediante comunicaciones de fecha 26 de marzo de 2018, se solicitó a las Naciones Unidas y sus Estados Miembros, así como a la Unión Africana, que notificaran a la Secretaría de la Corte, a más tardar el 15 de junio de 2018, si tenían previsto participar en el procedimiento oral.

15. Dentro del plazo prorrogado fijado por la Corte en su providencia de 17 de enero de 2018 se recibieron en la Secretaría de la Corte obser- 
vaciones por escrito presentadas (por orden de recepción) por la Unión Africana, Serbia, Nicaragua, el Reino Unido de Gran Bretaña e Irlanda del Norte, Mauricio, Seychelles, Guatemala, Chipre, las Islas Marshall, los Estados Unidos de América y la Argentina.

16. Tras recibir esas observaciones por escrito, el Secretario de la Corte, mediante comunicaciones de fecha 16 de mayo de 2018, informó a los Estados que habían presentado exposiciones escritas, así como a la Unión Africana, que se habían presentado observaciones por escrito y que dichas observaciones podían descargarse desde un sitio web específico.

17. El 22 de mayo de 2018, el Secretario de la Corte transmitió un conjunto completo de las observaciones por escrito a todos los Estados que habían presentado esas observaciones, así como a la Unión Africana.

18. El Secretario de la Corte, mediante cartas de fecha 29 de mayo de 2018, transmitió a las Naciones Unidas y a todos sus Estados Miembros que no habían participado en el procedimiento escrito un conjunto completo de las exposiciones escritas y observaciones por escrito presentadas a la Secretaría de la Corte.

19. El Secretario de la Corte, mediante cartas de fecha 21 de junio de 2018, transmitió a las Naciones Unidas y sus Estados Miembros, así como a la Unión Africana, la lista de los participantes en el procedimiento oral e incluyó un calendario detallado de dicho procedimiento.

20. El Secretario de la Corte, mediante cartas de fecha 26 de junio de 2018, informó a los Estados Miembros de las Naciones Unidas que participarían en el procedimiento oral, así como a la Unión Africana, de determinados acuerdos prácticos relativos a la organización de ese procedimiento.

21. En una carta de 2 de julio de 2018, Filipinas informó a la Corte de que ya no formularía ninguna exposición durante el procedimiento oral. El Secretario de la Corte, mediante cartas de fecha 10 de julio de 2018, informó al respecto a los Estados Miembros de las Naciones Unidas que participarían en el procedimiento oral y a la Unión Africana.

22. De conformidad con el artículo 106 de su Reglamento, la Corte decidió poner a disposición del público las exposiciones escritas y observaciones por escrito que se le habían presentado con efecto a partir de la apertura del procedimiento oral. 
23. Durante las audiencias celebradas del 3 al 6 de septiembre de 2018, la Corte escuchó exposiciones orales en el orden que se indica a continuación:

En nombre de la Repú- Su Excelencia Sir Anerood Jugnauth, GCSK, blica de Mauricio: $\quad$ KCMG, QC, Ministro Mentor, Ministro de Defensa y Ministro para Rodrigues de la República de Mauricio,

Sr. Pierre Klein, Profesor de la Universidad Libre de Bruselas,

Sra. Alison Macdonald, QC, abogada en Matrix Chambers (Londres),

Sr. Paul S. Reichler, abogado en Foley Hoag LLP, miembro del Colegio de Abogados del Distrito de Columbia,

Sr. Philippe Sands, QC, Profesor de Derecho Internacional en el University College London, abogado en Matrix Chambers (Londres);

En nombre del Reino

Sr. Robert Buckland, QC, MP, Procurador General, Unido de Gran Bretaña Sr. Samuel Wordsworth, QC, miembro del Colegio e Irlanda del Norte: de Abogados de Inglaterra y Gales, Essex Court Chambers,

Sra. Philippa Webb, miembro del Colegio de Abogados de Inglaterra y Gales, 20 Essex Street Chambers,

Sir Michael Wood, KCMG, miembro del Colegio de Abogados de Inglaterra y Gales, 20 Essex Street Chambers;

En nombre de la Repú- Sra. J. G. S. de Wet, Jefa de la Asesoría Jurídica del blica de Sudáfrica: Estado (Derecho Internacional) del Departamento de Relaciones Internacionales y Cooperación;

En nombre de la Excmo. Sr. Christophe Eick, Embajador, Asesor República Federal de Jurídico del Ministerio Federal de Relaciones Alemania: Exteriores (Berlín), 
Sr. Andreas Zimmermann, Profesor de Derecho Internacional de la Universidad de Postdam;

En nombre de la República Argentina:

En nombre de Australia:

En nombre de Belice:

En nombre de la República de Botswana:

En nombre de la República Federativa del Brasil:

En nombre de la República de Chipre:
Excmo. Sr. Mario Oyarzábal, Embajador, Asesor Jurídico del Ministerio de Relaciones Exteriores y Culto,

Sr. Marcelo Kohen, Profesor de Derecho Internacional del Instituto Superior de Estudios Internacionales y de Desarrollo de Ginebra, miembro y secretario general del Instituto de Derecho Internacional;

Sr. Bill Campbell, QC,

Sr. Stephen Donoghue, QC, Procurador General de Australia;

Sr. Ben Juratowitch, QC, abogado en Belice y admitido para ejercer en Inglaterra y Gales y en Queensland (Australia), Freshfields Bruckhaus Deringer;

Sr. Chuchuchu Nchunga, Adjunto del Fiscal del Estado de la Fiscalía General (Botswana),

Sr. Shotaro Hamamoto, Profesor de Derecho Internacional de la Universidad de Kyoto (Japón);

Excma. Sra. Regina Maria Cordeiro Dunlop, Embajadora de la República Federativa del Brasil en el Reino de los Países Bajos;

Excmo. Sr. Costas Clerides, Fiscal General de la República de Chipre,

Sra. Mary-Ann Stavrinides, Procuradora de la República de la Oficina de Asuntos Jurídicos de la República de Chipre,

Sr. Polyvios G. Polyviou, Chryssafinis \& Polyviou LLC;

En nombre de los Estados Unidos de América:
Sra. Jennifer G. Newstead, Asesora Jurídica del Departamento de Estado de los Estados Unidos; 
En nombre de la Repú-

blica de Guatemala:

En nombre de la

República de las Islas

Marshall:

En nombre de la Repú-

blica de la India:

En nombre del Estado

de Israel:

En nombre de la Repú-

blica de Kenya:
Sr. Lesther Antonio Ortega Lemus, Ministro Consejero, Correpresentante de Guatemala,

Excma. Sra. Gladys Marithza Ruiz Sánchez De Vielman, Embajadora, Representante de Guatemala;

Sr. Caleb W. Christopher, Asesor Jurídico de la Misión Permanente de la República de las Islas Marshall ante las Naciones Unidas (Nueva York);

Excmo. Sr. Venu Rajamony, Embajador de la India ante el Reino de los Países Bajos;

Sr. Tal Becker, Asesor Jurídico del Ministerio de Relaciones Exteriores,

Sr. Roy Schöndorf, Fiscal General Adjunto (Derecho Internacional) del Ministerio de Justicia;

Excmo. Sr. Lawrence Lenayapa, Embajador de la República de Kenya ante el Reino de los Países Bajos,

Sra. Pauline Mcharo, Jefa Adjunta del Abogado del Estado de la Fiscalía General de Kenya;

En nombre de la República de Nicaragua:

En nombre de la República Federal de Nigeria:

En nombre Serbia: de la República de

En nombre del Tailandia: Reino de

En nombre Vanuatu: de la República de
Excmo. Sr. Carlos José Argüello Gómez,

Embajador de Nicaragua ante el Reino de los Países Bajos;

Sr. Dayo Apata, Procurador General de la República Federal de Nigeria, Secretario Permanente del Ministerio Federal de Justicia;

Sr. Aleksandar Gajić, Asesor Jurídico Principal del Ministerio de Relaciones Exteriores;

Excmo. Sr. Virachai Plasai, Embajador del Reino de Tailandia ante los Estados Unidos de América;

Sr. Robert McCorquodale, Brick Court Chambers, miembro del Colegio de Abogados de Inglaterra y Gales, 
Sra. Jennifer Robinson, Doughty Street

Chambers, miembro del Colegio de Abogados de Inglaterra y Gales;

En nombre Zambia: de la República de

En nombre de la Unión Africana:
Sr. Likando Kalaluka, SC, Fiscal General,

Sr. Dapo Akande, Profesor de Derecho Internacional Público de la Universidad de Oxford;

Excma. Sra. Namira Negm, Embajadora, Asesora Jurídica de la Unión Africana y Directora de la Dirección del Departamento de Asuntos Jurídicos,

Sr. Mohammed Gomaa, Consejero Jurídico y Árbitro,

Sr. Makane Moïse Mbengue, Profesor de Derecho Internacional de la Universidad de Ginebra y Profesor Afiliado del Instituto de Estudios Políticos (París).

24. En las audiencias, un miembro de la Corte planteó una pregunta a Mauricio, que respondió por escrito, conforme a lo solicitado, dentro del plazo prescrito. Una vez que la Corte hubo decidido que los demás participantes podían presentar comentarios u observaciones sobre la respuesta dada por Mauricio, se recibieron observaciones por escrito en la Secretaría de la Corte presentadas (por orden de recepción) por la Unión Africana, la Argentina, el Reino Unido de Gran Bretaña e Irlanda del Norte y los Estados Unidos de América. Otro miembro de la Corte planteó una cuestión a todos los participantes en el procedimiento oral, a la qu e Australia, Botswana y Vanuatu, Nicaragua, el Reino Unido de Gran Bretaña e Irlanda del Norte, Mauricio, la Argentina, los Estados Unidos de América y Guatemala (por ese orden) respondieron por escrito, conforme a lo solicitado. Una vez que la Corte hubo decidido que los demás participantes podían presentar comentarios u observaciones sobre las respuestas dadas, Mauricio, la Unión Africana y los Estados Unidos de América presentaron esos comentarios u observaciones por escrito.

$$
* * *
$$




\section{Acontecimientos que llevaron a la aprobación de la solicitud de opinión consultiva}

25. Antes de examinar los acontecimientos que llevaron a la aprobación de la solicitud de opinión consultiva, la Corte recuerda que la República de Mauricio está integrada por un grupo de islas del océano Índico con una extensión aproximada de $1.950 \mathrm{~km} 2$. La isla principal de Mauricio está situada a unos $2.200 \mathrm{~km}$ al sudoeste del archipiélago de Chagos, a unos $900 \mathrm{~km}$ al este de Madagascar, a unos $1.820 \mathrm{~km}$ al sur de Seychelles y a unos $2.000 \mathrm{~km}$ de la costa oriental del continente africano.

26. El archipiélago de Chagos está integrado por una serie de islas y atolones. La isla más grande es Diego García, situada en el sudeste del archipiélago. Con una superficie de unos $27 \mathrm{~km} 2$, Diego García representa más de la mitad de la superficie total del archipiélago.

27. Aunque Mauricio fue ocupada por los Países Bajos entre 1638 y 1710, la primera administración colonial de Mauricio fue establecida en 1715 por Francia, que la llamó Île de France. En 1810 los británicos conquistaron la Ille de France y cambiaron su nombre por el de Mauricio. En virtud del Tratado de París de 1814, Francia cedió Mauricio y todas sus dependencias al Reino Unido.

28. Entre 1814 y 1965 el archipiélago de Chagos estuvo administrado por el Reino Unido como una dependencia de la colonia de Mauricio. Ya desde 1826 las islas del archipiélago de Chagos fueron incluidas por el Gobernador Lowry-Cole en las dependencias de Mauricio. Las islas fueron descritas también como dependencias de Mauricio en varias ordenanzas, entre ellas las formuladas por los Gobernadores de Mauricio en 1852 y 1872. La Orden relativa a la Constitución de Mauricio de 26 de febrero de 1964 (en lo sucesivo, la "Orden relativa a la Constitución de Mauricio de 1964”), promulgada por el Gobierno del Reino Unido, definió la colonia de Mauricio en el artículo 90, párrafo 1, como "la isla Mauricio y las dependencias de Mauricio”.

29. De conformidad con la resolución de la Asamblea General 66 (I), de 14 de diciembre de 1946, el Reino Unido, en calidad de Potencia administradora, transmitió regularmente a la Asamblea General, en virtud de lo dispuesto en el Artículo 73 e de la Carta de las Naciones Unidas, información relativa a Mauricio como Territorio No Autónomo. 
La información presentada por el Reino Unido se incluyó en varios informes de la Cuarta Comisión (Comisión Política Especial y de Descolonización) de la Asamblea General. En muchos de esos informes, las islas del archipiélago de Chagos, y en ocasiones el propio archipiélago de Chagos, reciben la denominación de dependencias de Mauricio. Según el informe de 1947, Mauricio está integrado por la isla de Mauricio y sus dependencias, entre las cuales se mencionan la isla de Rodríguez y el grupo de las Islas Aceite, cuya isla principal es Diego García. El informe de 1948 denominó colectivamente a todas las islas como "Mauricio". El informe de 1949 afirmaba que "hay una serie de islas repartidas por el océano Índico dependientes de Mauricio de las cuales la más importante es Rodríguez [...]. Otras dependencias son el archipiélago de Chagos [...], Agalega y Cargados Charajos".

30. El 14 de diciembre de 1960, la Asamblea General aprobó la resolución $1514(\mathrm{XV})$, titulada "Declaración sobre la Concesión de la Independencia a los Países y Pueblos Coloniales" (en lo sucesivo, la "resolución 1514 (XV)"). El 27 de noviembre de 1961, la Asamblea General, en su resolución 1654 (XVI), estableció el Comité Especial de Descolonización de las Naciones Unidas (en lo sucesivo, el "Comité de los Veinticuatro") para supervisar la aplicación de la resolución 1514 (XV).

31. En febrero de 1964 se iniciaron las conversaciones entre los Estados Unidos de América (en lo sucesivo, los "Estados Unidos") y el Reino Unido relativas al uso por los Estados Unidos de ciertas islas de propiedad británica en el océano Índico. Los Estados Unidos expresaron su interés en establecer instalaciones militares en la isla de Diego García.

32. El 29 de junio de 1964, el Reino Unido también inició conversaciones con el Primer Ministro de la colonia de Mauricio en relación con la separación del archipiélago de Chagos de Mauricio. En Lancaster House, las conversaciones entre representantes de la colonia de Mauricio y el Gobierno del Reino Unido llevaron a la celebración, el 23 de septiembre de 1965, de un acuerdo (en lo sucesivo, el "acuerdo de Lancaster House", descrito con más detalle en el párrafo 108).

33. El 8 de noviembre de 1965 , mediante la Orden relativa al Territorio Británico del Océano Índico de 1965, el Reino Unido estableció una nueva col onia conocida como el Territorio Británico del Océano Índico, integrado por el archipiélago de Chagos, separado de Mauricio, y las islas Aldabra, Farquhar y Desroches, separadas de Seychelles. 
34. El 16 de diciembre de 1965, la Asamblea General aprobó la resolución 2066 (XX), relativa a la "Cuestión de la isla Mauricio", en la que expresó profunda inquietud por la separación de ciertas islas del territorio de Mauricio a fin de establecer en ellas una base militar e invitó a la "Potencia administradora a no adoptar ninguna medida que pudiera desmembrar el Territorio de la Isla Mauricio y violar su integridad territorial".

35. El 20 de diciembre de 1966, la Asamblea General aprobó la resolución 2232 (XXI) sobre varios territorios, entre ellos Mauricio. La resolución reiteró que:

"todo intento encaminado a quebrantar total o parcialmente la unidad nacional y la integridad territorial de los territorios coloniales y a establecer bases e instalaciones militares en esos territorios es incompatible con los propósitos y principios de la Carta de las Naciones Unidas y con la resolución 1514 (XV) de la Asamblea General".

36. Las conversaciones entre el Reino Unido y los Estados Unidos dieron lugar a la celebración, el 30 de diciembre de 1966, del Acuerdo sobre la Disponibilidad d el Territorio Británico del Océano Índico para Fines de Defensa y a la celebración de un Acta Convenida en la misma fecha.

37. Sobre la base del Acuerdo de 1966, los Estados Unidos y el Reino Unido acordaron que el Gobierno del Reino Unido adoptaría las "medidas administrativas" necesarias para garantizar que se satisficieran sus necesidades en materia de defensa. El Acta Convenida dispuso que, entre las medidas administrativas que debían adoptarse, se encontraba la de "reasentar a los habitantes" de las islas. Los habitantes del archipiélago de Chagos reciben la denominación de chagosianos y, en ocasiones, "ilois" o "isleños". En la presente opinión se utilizan estos términos indistintamente.

38. El 10 de mayo de 1967, el Primer Subcomité del Comité de los Veinticuatro informó de que:

"Al crear un nuevo territorio, el Territorio Británico del Océano Índico, compuesto por islas separadas de Mauricio y Seychelles, la Potencia administradora sigue violando la integridad 
territorial de esos Territorios No Autónomos y desafiando las resoluciones 2066 (XX) y 2232 (XXI) de la Asamblea General".

39. Los días 15, 17 y 19 de junio de 1967, el Comité de los Veinticuatro examinó el informe del Primer Subcomité y aprobó una resolución sobre Mauricio. En dicha resolución, el Comité "lamenta el desmembramiento de Mauricio y Seychelles por la Potencia administradora, lo que viola su integridad territorial en contravención de las resoluciones de la Asamblea General 2066 (XX) y 2232 (XXI), e insta a la Potencia administradora a que devuelva a esos territorios las islas que fueron separadas de ellos".

40. El 7 de agosto de 1967 se celebraron elecciones generales en Mauricio, en las que se impusieron los partidos políticos a favor de la independencia.

41. El 19 de diciembre de 1967, la Asamblea General aprobó la resolución 2357 (XXII) sobre varios territorios, entre ellos Mauricio, y reafirmó lo que había declarado en la resolución 2232 (XXI) (véase el párrafo 35).

42. El 12 de marzo de 1968, Mauricio se convirtió en un Estado independiente y el 26 de abril de 1968 fue admitido como Miembro de las Naciones Unidas. Sir Seewoosagur Ramgoolam fue el primer Ministro de la República de Mauricio. En el artículo 111, párrafo 1, de la Constitución de 1968 de Mauricio, promulgada por el Gobierno del Reino Unido antes de la independencia el 4 de marzo de 1968, se definió a Mauricio como "los territorios que constituían la colonia de Mauricio inmediatamente antes del 12 de marzo de 1968". Esa definición no incluía al archipiélago de Chagos en el territorio de Mauricio.

43. Entre 1967 y 1973, el Reino Unido impidió regresar a toda la población del archipiélago de Chagos o la expulsó a la fuerza y le impidió regresar posteriormente. La principal expulsión forzosa de la población de Diego García tuvo lugar en julio y septiembre de 1971.

44. El 11 de abril de 1979, en un debate sobre la separación del archipiélago de Chagos, el Primer Ministro Ramgoolam declaró ante el Parlamento de Mauricio: "No teníamos elección".

45. En julio de 1980, la Organización de la Unidad Africana aprobó la resolución 99 (XVII) (1980), en la que se "exige" que Diego García "se devuelva a Mauricio de manera incondicional". 
46. El 9 de octubre de 1980, el Primer Ministro de Mauricio, en el trigésimo quinto período de sesiones de la Asamblea General de las Naciones Unidas, declaró que el Territorio Británico del Océano Índico debía disolverse y que el territorio debía restituirse a Mauricio como parte de su patrimonio natural.

47. En julio de 2000, la Organización de la Unidad Africana aprobó la decisión AHG/Dec.159 (XXXVI) (2000), en la que expresaba su preocupación por el hecho de que el archipiélago de Chagos hubiera sido "desgajado ilegalmente por la Potencia colonial de Mauricio antes de su independencia, en violación de la resolución 1514 de las Naciones Unidas".

48. El 1 de abril de 2010, el Reino Unido anunció la creación de una zona marina protegida en el archipiélago de Chagos y sus alrededores. El 20 de diciembre de 2010, Mauricio inició un proceso contra el Reino Unido, de conformidad con el artículo 287 de la Convención de las Naciones Unidas sobre el Derecho del Mar (en adelante, la "Convención"), ante un tribunal arbitral constituido con arreglo al anexo VII de la Convención, en el que se cuestionaba la creación por el Reino Unido de una zona marina protegida. En ese proceso, Mauricio alegó, entre otras cosas, que: 1) el Reino Unido no estaba facultado para declarar una zona marina protegida ni otras zonas marítimas en el archipiélago de Chagos y sus alrededores ya que no era un Estado ribereño con arreglo a la Convención; 2) el Reino Unido no estaba facultado para declarar unilateralmente una zona marina protegida ni otras zonas marítimas, ya que Mauricio tenía derechos como Estado ribereño con arreglo al artículo 56, párrafo 1, y al artículo 76, párrafo 8, de la Convención; 3) el Reino Unido no debía adoptar medida alguna para evitar que la Comisión de Límites de la Plataforma Continental formulara recomendaciones a Mauricio respecto de cualquier pretension que Mauricio pudiera hacer ante esa Comisión respecto del archipiélago de Chagos; y 4) la zona marina protegida era incompatible con las obligaciones del Reino Unido dimanantes de la Convención.

49. El 27 de julio de 2010, la Unión A fricana aprobó la decisión 331 (2010), en la que declaró que el archipiélago de Chagos, incluida la isla de Diego García, había sido separado "del territorio de Mauricio por la antigua Potencia colonial en violación de las resoluciones de la Asamblea General 1514 (XV), de 14 de diciembre de 1960, y 2066 (XX), de 16 de diciembre de 1965, que prohíben a las Potencias coloniales desmembrar territorios coloniales antes de conceder la independencia”. 
50. El 18 de marzo de 2015, el tribunal arbitral constituido con arreglo al anexo VII de la Convención dictó un laudo en el Arbitraje sobre la zona marina protegida de Chagos entre Mauricio y el Reino Unido (en lo sucesivo, el "Arbitraje sobre la zona marina protegida de Chagos"). El tribunal arbitral estimó, en su laudo, que no tenía competencia para considerar las pretensiones primera, segunda y tercera de Mauricio, pero que sí era competente para considerar su cuarta pretensión. Con respecto a la primera pretensión, el tribunal arbitral observó que "la controversia entre las partes respecto de la soberanía sobre el archipiélago de Chagos no se refiere a la interpretación o la aplicación" de la Convención. En cuanto al fondo de la cuestión, el tribunal arbitral consideró, entre otras cosas, que, al establecer la zona marina protegida en torno al archipiélago de Chagos, el Reino Unido había incumplido sus obligaciones en virtud de los artículos 2, párrafo 3, 56, párrafo 2, y 194, párrafo 4, de la Convención, y que el compromiso asumido por el Reino Unido de devolver el archipiélago de Chagos a Mauricio cuando ya no fuera necesario para fines de defensa era jurídicamente vinculante.

51. El 30 de diciembre de 2016 llegó a su fin el período de 50 años previsto en el Acuerdo de 1966; sin embargo, se prorrogó por un nuevo período de 20 años, de conformidad con sus disposiciones.

52. El 30 de enero de 2017, la Asamblea de la Unión Africana aprobó la resolución AU/Res.1 (XXVIII) sobre el archipiélago de Chagos, que resolvió, entre otras cosas, apoyar a Mauricio con miras a garantizar "la conclusión del proceso de descolonización de la República de Mauricio".

53. El 23 de junio de 2017, la Asamblea General aprobó la resolución 71/292, en la que se solicitaba una opinión consultiva de la Corte (véase el párrafo 1). Tras recordar los acontecimientos que llevaron a la aprobación de esa solicitud, la Corte pasa ahora a examinar las cuestiones relativas a su competencia y facultad discrecional. 


\section{Competencia y facultad discrecional}

54. Cuando la Corte tiene ante sí una solicitud de opinión consultiva, debe examinar en primer lugar si es competente para emitir la opinión solicitada y, en caso afirmativo, si existe alguna razón por la que la Corte deba, en el ejercicio de su facultad discrecional, negarse a responder a la solicitud (véase Legalidad de la amenaza o el empleo de armas nucleares, opinión consultiva, I.C.J. Reports 1996 (I), pág. 232, párr. 10; Consecuencias jurídicas de la construcción de un muro en el Territorio Palestino Ocupado, opinión consultiva, I.C.J. Reports 2004 (I), pág. 144, párr. 13; Conformidad con el derecho internacional de la declaración unilateral de independencia relativa a Kosovo, opinión consultiva, I.C.J. Reports 2010 (II), pág. 412, párr. 17).

\section{A. Competencia}

55. La competencia de la Corte para emitir una opinión consultiva se basa en el Artículo 65, párrafo 1, de su Estatuto, que dispone que "la Corte podrá emitir opiniones consultivas respecto de cualquier cuestión jurídica, a solicitud de cualquier organismo autorizado para ello por la Carta de las Naciones Unidas, o de acuerdo con las disposiciones de la misma".

56. La Corte señala que la Asamblea General es competente para solicitar una opinión consultiva en virtud del Artículo 96, párrafo 1, de la Carta, que dispone que "la Asamblea General [...] podr[á] solicitar de la Corte Internacional de Justicia que emita una opinión consultiva sobre cualquier cuestión jurídica”.

57. La Corte pasa ahora a examinar el requisito establecido en el Artículo 96 de la Carta y el Artículo 65 de su Estatuto de que la opinión consultiva debe ser sobre una "cuestión jurídica".

58. En el presente procedimiento, la primera cuestión planteada a la Corte es si el proceso de descolonización de Mauricio se completó con arreglo a derecho y teniendo en cuenta el derecho internacional cuando obtuvo la independencia después de la separación del archipiélago de Chagos. La segunda cuestión hace referencia a las consecuencias en virtud del derecho internacional que se derivan de que el Reino Unido siga administrando el archipiélago de Chagos. La Corte considera que una solicitud presentada por la Asamblea General para obtener una opinión 
consultiva a fin de examinar una situación a la luz del derecho internacional constituye una cuestión jurídica.

59. Por consiguiente, la Corte concluye que la solicitud se ha realizado de conformidad con la Carta y que las dos cuestiones sometidas son de carácter jurídico.

60. Uno de los participantes en el presente procedimiento alega que la Corte carece de competencia porque las cuestiones planteadas "parecen guardar relación con un tema, pero [...] en realidad guardan relación con otro". Además, afirma que no se ha formulado "en términos precisos la cuestión respecto de la cual se [hace] la consulta" en el sentido del Artículo 65, párrafo 2, del Estatuto. Según ese mismo participante, las cuestiones planteadas a la Corte no reflejan los problemas reales, que están relacionados con la soberanía y no con la descolonización.

61. La Corte opina que los argumentos planteados en el presente procedimiento en relación con el Artículo 65, párrafo 2, de su Estatuto no la privan de competencia para emitir la opinión consultiva. Al pronunciarse sobre argumentos similares en su opinión consultiva sobre las Consecuencias jurídicas de la construcción de un muro en el Territorio Palestino Ocupado, la Corte observó que "la falta de claridad en la redacción de una cuestión no podría privar a la Corte de su jurisdicción. En todo caso, en razón de tal incertidumbre la Corte deberá precisar la interpretación que debe darse a la cuestión, cosa que ha hecho con frecuencia " (opinión consultiva, I.C.J. Reports 2004 (I), págs. 153 y 154, párr. 38). La Corte examinará esos argumentos más adelante, en los párrafos 135 a 137.

62. En consecuencia, la Corte tiene competencia para emitir la opinión consultiva solicitada por la resolución 71/292 de la Asamblea General.

\section{B. Facultad discrecional}

63. El hecho de que la Corte tenga competencia no significa, sin embargo, que esté obligada a ejercerla:

"En el pasado, la Corte ha recordado en reiteradas ocasiones que el párrafo 1 del Artículo 65 de su Estatuto, que establece que 'la Corte podrá emitir opiniones consultivas...' [...] debería interpretarse en el sentido de que la Corte tiene la facultad 
discrecional para negarse a emitir una opinión consultiva aun cuando se hayan reunido los requisitos necesarios para que tenga competencia" (Consecuencias jurídicas de la construcción de un muro en el Territorio Palestino Ocupado, opinión consultiva, I.C.J. Reports 2004 (I), pág. 156, párr. 44; Conformidad con el derecho internacional de la declaración unilateral de independencia relativa a Kosovo, opinión consultiva, I.C.J. Reports 2010 (II), págs. 415 y 416, párr. 29).

64. La facultad discrecional de responder o no a una solicitud de opinión consultiva existe a fin de proteger la integridad de la función judicial de la Corte como órgano judicial principal de las Naciones Unidas (Consecuencias jurídicas de la construcción de un muro en el Territorio Palestino Ocupado, opinión consultiva, I.C.J. Reports 2004 (I), págs. 156 y 157, párrs. 44 y 45; Conformidad con el derecho internacional de la declaración unilateral de independencia relativa a Kosovo, opinión consultiva, I.C.J. Reports 2010 (II), págs. 415 y 416, párr. 29).

65. No obstante, la Corte es consciente de que su respuesta a una solicitud de opinión consultiva "representa su participación en las actividades de la Organización y, en principio, no debería denegarse" (Interpretación de los tratados de paz con Bulgaria, Hungría y Rumania (primera fase), opinión consultiva, I.C.J. Reports 1950, pág. 71; Controversia relacionada con la inmunidad judicial de un Relator Especial de la Comisión de Derechos Humanos, opinión consultiva, I.C.J. Reports 1999 (I), págs. 78 y 79, párr. 29; Consecuencias jurídicas de la construcción de un muro en el Territorio Palestino Ocupado, opinión consultiva, I.C.J. Reports 2004 (I), pág. 156, párr. 44). Así, según su jurisprudencia reiterada, solo la existencia de "razones imperiosas" puede llevar a la Corte a negarse a dar su opinión en respuesta a una solicitud que sea de su competencia (Consecuencias jurídicas de la construcción de un muro en el Territorio Palestino Ocupado, opinión consultiva, I.C.J. Reports 2004 (1), pág. 156, párr. 44; Conformidad con el derecho internacional de la declaración unilateral de independencia relativa a Kosovo, opinión consultiva, I.C.J. Reports 2010 (II), pág. 416, párr. 30).

66. La Corte debe cerciorarse de la conveniencia de ejercer su función judicial en el presente procedimiento. Así pues, considerará detenidamente si existen razones imperiosas para negarse a responder a la solicitud de la Asamblea General.

67. Algunos de los participantes en el presente procedimiento argumentan que existen "razones imperiosas" para que la Corte ejerza su 
facultad discrecional de negarse a emitir la opinión consultiva solicitada. Entre las razones planteadas por estos participantes se encuentran, en primer lugar, que el procedimiento consultivo no es adecuado para la determinación de cuestiones de hecho complejas y controvertidas; en segundo lugar, que la respuesta de la Corte no ayudaría a la Asamblea General en el desempeño de sus funciones; en tercer lugar, que sería inapropiado que la Corte volviera a examinar una cuestión ya resuelta por el tribunal arbitral constituido con arreglo al anexo VII de la Convención en el Arbitraje sobre la zona marina protegida de Chagos; y, en cuarto lugar, que las cuestiones planteadas en el presente procedimiento se refieren a una controversia bilateral pendiente entre dos Estados que no han dado su consentimiento para que sea resuelta por la Corte.

68. A continuación la Corte procederá a examinar estos argumentos.

\section{Cuestión de si el procedimiento consultivo es adecuado para la determinación de cuestiones de hecho complejas y controvertidas}

69. Algunos de los participantes alegan que las cuestiones planteadas suscitan cuestiones de hecho complejas y controvertidas que no se pueden determinar adecuadamente en un procedimiento consultivo. Esos participantes afirman que, en el presente procedimiento, la Corte no dispone de información ni pruebas suficientes para llegar a una conclusión sobre las complejas y controvertidas cuestiones de hecho que se le han presentado.

70. Otros participantes sostienen que las cuestiones de hecho presentadas ante la Corte no son complejas y que lo que realmente importa es la interpretación que haga la Corte de esos hechos.

71. La Corte recuerda que, en su opinión consultiva sobre el Caso relativo al Sáhara Occidental, concluyó, en respuesta al mismo argumento, que lo decisivo era si disponía de

"información y pruebas suficientes para poder pronunciarse sobre cualquier cuestión de hecho controvertida cuya determinación sea necesaria para emitir una opinión en condiciones compatibles con su carácter judicial" (I.C.J. Reports 1975, págs. 28 y 29, párr. 46). 
72. Además, la Corte recuerda que, en su opinión consultiva sobre las Consecuencias jurídicas que tiene para los Estados la continuación de la presencia de Sudáfrica en Namibia (Africa Sudoccidental), no obstante lo dispuesto en la resolución 276 (1970) del Consejo de Seguridad, sostuvo que

"para pronunciarse sobre cuestiones jurídicas, también debe conocer y tener en cuenta las cuestiones de hecho pertinentes y, en caso necesario, pronunciarse al respecto" (I.C.J. Reports 1971, pág. 27, párr. 40).

73. La Corte observa la abundancia de material que se le ha presentado, incluido un voluminoso legajo de las Naciones Unidas. Además, muchos participantes han presentado exposiciones escritas y observaciones por escrito y han formulado exposiciones orales que contienen información pertinente para responder a las cuestiones. En total, 31 Estados y la Unión Africana presentaron exposiciones escritas, 10 de esos Estados y la Unión Africana presentaron observaciones por escrito sobre esas exposiciones y 22 Estados y la Unión Africana formularon exposiciones orales. La Corte observa que la información proporcionada por los participantes incluye los diversos documentos oficiales elaborados en la década de 1960, como los del Reino Unido relativos a la separación del archipiélago de Chagos y el acceso de Mauricio a la independencia.

74. Por consiguiente, la Corte considera que en el presente procedimiento hay información suficiente sobre los hechos que se le han presentado para poder emitir la opinión solicitada. En consecuencia, la Corte no puede negarse a responder a las cuestiones planteadas.

\section{Cuestión de si la respuesta de la Corte ayudaría a la Asamblea General en el desempeño de sus funciones}

75. Algunos participantes alegan que la opinión consultiva solicitada no ayudaría a la Asamblea General en el desempeño adecuado de sus funciones. Estos participantes sostienen que la Asamblea General no ha participado activamente en el proceso de descolonización de Mauricio desde 1968. En particular, afirma n que, cuando pasó a ser independiente en marzo de 1968, Mauricio fue eliminado de la lista de territorios bajo la supervisión del Comité de los Veinticuatro y que el archipiélago de Chagos nunca se añadió a esa lista. Otros participantes argumentan que la respuesta de la Corte sí sería de utilidad para la Asamblea General, 
que, después de 1968, siguió examinando la cuestión de Mauricio y la separación del archipiélago de Chagos.

76. La Corte considera que no le corresponde determinar cuál sería la utilidad de su respuesta para el órgano solicitante. Corresponde al órgano solicitante, la Asamblea General, determinar "si necesita la opinión para el desempeño adecuado de sus funciones" (Conformidad con el derecho internacional de la declaración unilateral de independencia relativa a Kosovo, opinión consultiva, I.C.J. Reports 2010 (II), pág. 417, párr. 34). La Corte recuerda que, en su opinión consultiva sobre la Legalidad de la amenaza o el empleo de armas nucleares, no aceptó el argumento de que la Corte debía negarse a responder a la solicitud de la Asamblea General porque esta no le había explicado los fines para los que solicitaba la opinión. La Corte observó que

"no cabe a la Corte decidir si la Asamblea necesita la opinión consultiva para el desempeño de sus funciones. La Asamblea General tiene derecho a decidir por sí misma, a la luz de sus propias necesidades, sobre la utilidad de una opinión" (I.C.J. Reports 1996 (I), pág. 237, párr. 16).

77. En la opinión consultiva sobre las Consecuencias jurídicas de la construcción de un muro en el Territorio Palestino Ocupado, la Corte afirmó que "no puede pretender que su evaluación de la utilidad de la opinión solicitada sustituya la del órgano que la solicita” (I.C.J. Reports 2004 (I), pág. 163, párr. 62). La Corte recuerda que, "en cualquier caso, no corresponde a la Corte decidir en qué medida o hasta qué punto su opinión afectará a la actuación de la Asamblea General" (Caso relativo al Sábara Occidental, opinión consultiva, I.C.J. Reports 1975, pág. 37, párr. 73).

78. De ello se deduce que, en el presente procedimiento, la Corte no puede negarse a responder a las cuestiones que le ha planteado la Asamblea General en su resolución 71/292 alegando que su opinión no ayudaría a la Asamblea General en el desempeño de sus funciones.

\section{Cuestión de si sería apropiado que la Corte volviera a examinar una cuestión presuntamente resuelta por el tribunal arbitral constituido con arreglo al anexo VII de la Convención de las Naciones Unidas sobre el Derecho del Mar en el Arbitraje sobre la zona marina protegida de Chagos}


79. Algunos participantes argumentan que una opinión consultiva de la Corte reabriría cuestiones que el tribunal arbitral en el Arbitraje sobre la zona marina protegida de Chagos resolvió de manera vinculante para Mauricio y el Reino Unido.

80. Otros participantes afirman que el principio de cosa juzgada no es aplicable al presente procedimiento, ya que las mismas partes no pretenden litigar sobre una cuestión que ya ha sido resuelta definitivamente entre ellas en una causa anterior.

81. La Corte recuerda que su opinión "no la ofrece a los Estados, sino al órgano que esté facultado para solicitarla" (Interpretación de los tratados de paz con Bulgaria, Hungría y Rumania (primera fase), opinión consultiva, I.C.J. Reports 1950, pág. 71). La Corte observa que el principio de cosa juzgada no le impide emitir una opinión consultiva. Al responder a una cuestión presentada para que emita una opinión, la Corte examinará toda decisión judicial o arbitral pertinente. En cualquier caso, la Corte señala asimismo que las cuestiones que determinó el tribunal arbitral en el Arbitraje sobre la zona marina protegida de Chagos (véase el párrafo 50) no son las mismas que las presentadas ante la Corte en el presente procedimiento.

82. De lo anterior se infiere que la Corte no puede negarse a responder a las cuestiones fundándose en este motivo.

\section{Cuestión de si las cuestiones planteadas se refieren a una controversia pendiente entre dos Estados que no han dado su consentimiento para que sea resuelta por la Corte}

83. Algunos de los participantes argumentan que existe una controversia bilateral entre Mauricio y el Reino Unido respecto de la soberanía sobre el archipiélago de Chagos y que dicha controversia ocupa un lugar central en el procedimiento consultivo. Según esos participantes, para resolver las cuestiones en el presente procedimiento la Corte estaría obligada a pronunciarse sobre determinados aspectos clave, como el efecto del acuerdo de Lancaster House de 1965. Algunos participantes afirman que la controversia sobre la soberanía que surgió en la década de 1980 en las relaciones bilaterales es la "auténtica controversia" que motiva la solicitud. Estos participantes afirman además que las reclamaciones de Mauricio en el Arbitraje sobre la zona marina protegida de Chagos revelaron la existencia de una controversia territorial bilateral entre ese Estado y 
el Reino Unido. Por tanto, la emisión de una opinión consultiva contravendría "el principio de que un Estado no está obligado a someter una diferencia a arreglo judicial sin su consentimiento" (Caso relativo al Sáhara Occidental, opinión consultiva, I.C.J. Reports 1975, págs. 24 y 25, párrs. 32 y 33; Interpretación de los tratados de paz con Bulgaria, Hungría y Rumania (primera fase), opinión consultiva, I.C.J. Reports 1950, pág. 71).

84. Otros participantes sostienen que no existe ninguna controversia territorial entre el Reino Unido y Mauricio que impida a la Corte emitir la opinión consultiva solicitada. En particular, argumentan que las cuestiones planteadas a la Corte por la Asamblea General se sitúan en un marco de referencia más amplio, es decir, el derecho de la descolonización y el ejercicio del derecho a la libre determinación. Algunos de los participantes argumentan que la controversia entre Mauricio y el Reino Unido relativa a la soberanía territorial sobre el archipiélago de Chagos no podría haber surgido al margen de la cuestión de la descolonización ni puede desvincularse de esta cuestión. Otros participantes afirman que el Reino Unido, al comprometerse en 1965 a la devolución del archipiélago de Chagos a Mauricio cuando ya no fuera necesario para fines de defensa, reconoció que el archipiélago pertenecía a Mauricio y, en consecuencia, no puede existir ninguna controversia territorial.

85. La Corte recuerda que existiría una razón imperiosa para negarse a emitir una opinión consultiva cuando dicha respuesta tuviera "por efecto soslayar el principio de que un Estado no está obligado a someter una diferencia a arreglo judicial sin su consentimiento" (Caso relativo al Sáhara occidental, opinión consultiva, I.C.J. Reports 1975, pág. 25, párr. 33).

86. La Corte observa que las cuestiones que le ha planteado la Asamblea General se refieren a la descolonización de Mauricio. La Asamblea General no ha solicitado la opinión de la Corte para resolver una controversia territorial entre dos Estados. La finalidad de la solicitud de la Asamblea General es más bien recibir asistencia de la Corte para que la guíe en el desempeño de sus funciones con respecto a la descolonización de Mauricio. La Corte ya ha puesto de relieve que podría ser del interés de la Asamblea General solicitar una opinión consultiva que considere útil para desempeñar sus funciones con respecto a la descolonización:

"El propósito de la Asamblea General no ha sido someter a la Corte, por medio de una solicitud de opinión consultiva, una disputa o controversia jurídica con miras a ejercer, más adelante y 
sobre la base de la opinión de la Corte, sus facultades y funciones para el arreglo pacífico de esa disputa o controversia. El objeto de la solicitud es totalmente distinto: obtener de la Corte una opinión que la Asamblea General considere de ayuda para ejercer debidamente sus funciones con respecto a la descolonización del territorio " (Caso relativo al Sábara occidental, opinión consultiva, I.C.J. Reports 1975, págs. 26 y 27, párr. 39).

87. La Corte observa que la Asamblea General cuenta con un historial largo y acreditado en la lucha contra el colonialismo. Desde los primeros días de las Naciones Unidas, la Asamblea General ha desempeñado un papel activo en cuestiones de descolonización. El Artículo 1, párrafo 2, de la Carta establece que uno de los propósitos de las Naciones Unidas es el respeto al principio de la igualdad de derechos y al de la libre determinación de los pueblos. A este respecto, la Corte observa que el Capítulo XI de la Carta de las Naciones Unidas se refiere a los Territorios No Autónomos y que el primer artículo de ese Capítulo, el Artículo 73, dispone que las Potencias administradoras de los Territorios No Autónomos están obligadas, entre otras cosas, a "transmitir regularmente al Secretario General, a título informativo [...], la información estadística y de cualquier otra naturaleza técnica que verse sobre las condiciones económicas, sociales y educativas de los territorios por los cuales son respectivamente responsables". La Cuarta Comisión (Comisión Política Especial y de Descolonización) de la Asamblea General examinó esta información y la incluyó en sus informes. La labor de la Comisión continuó hasta 1961, cuando se estableció el Comité de los Veinticuatro.

88. Por consiguiente, la Corte concluye que se ha solicitado una opinión sobre la cuestión de la descolonización, que es tema de especial preocupación para las Naciones Unidas. Las cuestiones planteadas por la solicitud se sitúan en el marco de referencia más amplio de la descolonización, incluido el papel que desempeña la Asamblea General a este respecto, del que esas cuestiones son inseparables (Caso relativo al Sáhara Occidental, opinión consultiva, I.C.J. Reports 1975, pág. 26, párr. 38; Consecuencias jurídicas de la construcción de un muro en el Territorio Palestino Ocupado, opinión consultiva, I.C.J. Reports 2004 (I), pág. 159, párr. 50).

89. Además, la Corte observa que pueden existir diferencias de opinión sobre cuestiones jurídicas objeto de procedimientos consultivos (Consecuencias jurídicas que tiene para los Estados la continuación de la presencia 
de Sudáfrica en Namibia (África Sudoccidental), no obstante lo dispuesto en la resolución 276 (1970) del Consejo de Seguridad, opinión consultiva, I.C.J. Reports 1971, pág. 24, párr. 34). Sin embargo, el hecho de que la Corte tenga que pronunciarse sobre cuestiones jurídicas respecto de las cuales Mauricio y el Reino Unido han expresado opiniones divergentes no significa que, al responder a la solicitud, la Corte se enfrente a una controversia bilateral.

90. En esas circunstancias, la Corte no considera que la emisión de la opinión solicitada tenga por efecto soslayar el principio del consentimiento de un Estado al arreglo judicial de su controversia con otro Estado. Por consiguiente, la Corte no puede, en el ejercicio de su facultad discrecional, negarse a emitir la opinión fundándose en ese motivo.

91. En vista de cuanto antecede, la Corte concluye que no hay razones imperiosas para negarse a emitir la opinión solicitada por la Asamblea General.

\section{Contexto fáctico de la separación del archipiélago de Chagos de Mauricio}

92. La Corte observa que las cuestiones que le ha planteado la Asamblea General se refieren a la separación del archipiélago de Chagos de Mauricio y a las consecuencias jurídicas que se derivan de que el Reino Unido siga administrando el archipiélago de Chagos (véase el párrafo 1). Antes de abordar estas cuestiones, la Corte considera que es importante examinar las circunstancias de hecho que rodean la separación del archipiélago de Chagos de Mauricio, así como las relativas a la expulsión de los chagosianos de este territorio.

93. A este respecto, la Corte observa que, antes de la separación del archipiélago de Chagos de Mauricio, se celebraron conversaciones oficiales entre el Reino Unido y los Estados Unidos, así como entre el Gobierno del Reino Unido y los representantes de la colonia de Mauricio.

\section{A. Conversaciones entre el Reino Unido y los Estados Unidos sobre el archipiélago de Chagos}

94. En febrero de 1964 se iniciaron las conversaciones entre los Gobiernos del Reino Unido y los Estados Unidos sobre el "uso estratégico 
de ciertas islas de pequeño tamaño de propiedad británica en el océano Índico" para fines de defensa. Durante estas conversaciones, los Estados Unidos expresaron su interés en establecer un centro de comunicaciones militares en Diego García. Al término de las conversaciones, se acordó que la delegación del Reino Unido recomendaría a su Gobierno que se encargara de la adquisición de tierras, el reasentamiento de la población y la indemnización a expensas del Gobierno del Reino Unido; que el Gobierno de los Estados Unidos asumiría los costos de construcción y mantenimiento; y que el Gobierno del Reino Unido evaluaría con rapidez la viabilidad de desvincular la administración de Diego García y las otras islas del archipiélago de Chagos de la administración de Mauricio.

95. Según un memorando del Ministerio de Relaciones Exteriores del Reino Unido, el Reino Unido opinó que el curso de acción que mejor respondería a sus intereses principales parecía ser separar Diego García y otras islas del archipiélago de Chagos de Mauricio antes de la independencia de este y someter a esas islas a la administración directa del Reino Unido, y que esta medida podía tomarse por decreto. El Reino Unido consideró que tenía la facultad constitucional de adoptar esa medida sin el consentimiento de Mauricio, pero que ese enfoque lo expondría a las críticas de las Naciones Unidas. En ese mismo documento también se indicaba que dichas críticas perderían gran parte de su fuerza en caso de que el Reino Unido obtuviera previamente de los ministros de Mauricio su aceptación de la separación, ya fuera por medio de consentimiento positivo o por aquiescencia. El documento añadía que serviría mejor a los intereses del Reino Unido que la separación del archipiélago de Chagos se presentara a Mauricio como "un hecho consumado" o, a lo sumo, que se avisase a Mauricio de los planes del Reino Unido "en el último momento".

96. Según un documento interno desclasificado del Reino Unido de fecha 23 y 24 de septiembre de 1965 (Acta de las conversaciones entre el Reino Unido y los Estados Unidos sobre las instalaciones de defensa en el océano Índico, Reino Unido, FO 371/184529), los Gobiernos del Reino Unido y los Estados Unidos consideraron que, en lugar de separar las islas del archipiélago de Chagos de Mauricio y las islas de Aldabra, Farquhar y Desroches de Seychelles en dos operaciones distintas, serviría mejor a sus intereses efectuar la separación "como una operación única" a fin de evitar "una segunda confrontación" en las Naciones Unidas. Según el mismo documento, durante las conversaciones el Reino Unido explicó a los Estados Unidos que la separación del archipiélago de Chagos 
de Mauricio se llevaría a cabo en tres eta pas; en la última etapa estaba previsto que, cuando las instalaciones de defensa se instalaran en una isla, "esta estaría libre de población local civil".

97. Las conversaciones entre el Reino Unido y los Estados Unidos llevaron a la celebración del acuerdo de 1966 para el establecimiento de una base militar de los Estados Unidos en el archipiélago de Chagos (véase el párrafo 36).

\section{B. Conversaciones entre el Gobierno del Reino Unido y los representantes de la colonia de Mauricio sobre el archipiélago de Chagos}

98. La Orden relativa a la Constitución de Mauricio de 1964, promulgada por el Gobierno del Reino Unido, estableció una Asamblea Legislativa integrada por 40 miembros electos, la Presidencia y la Secretaría Principal ex officio y hasta 15 miembros designados por el Gobernador. Los miembros designados de la Asamblea Legislativa ocupaban su cargo a discreción del Gobernador. Se estableció un Consejo de Ministros para Mauricio integrado por entre 10 y 13 miembros designados, el Secretario Principal de Mauricio y el Primer Ministro de Mauricio; y miembros temporales que podrían sustituir a un miembro designado que estuviera enfermo o ausente de la isla de Mauricio. Los miembros del Consejo eran nombrados por el Gobernador, previa consulta con el Primer Ministro. Tenían que ser miembros de la Asamblea Legislativa. En el marco de las conversaciones entre el Gobierno del Reino Unido y los representantes de la colonia de Mauricio, esta estuvo representada por el Primer Ministro de Mauricio, o por el Primer Ministro y otros miembros del Consejo de Ministros.

99. En 1964, el Comité de los Veinticuatro denunció que la Constitución de Mauricio no permitía a los representantes del pueblo ejercer auténticos poderes y que esa autoridad se concentraba prácticamente por completo en manos del Gobierno del Reino Unido (véase el párrafo 172).

100. El 29 de junio de 1964, el Sr. John Rennie, Gobernador de Mauricio, debatió con Sir Seewoosagur Ramgoolam, Primer Ministro de Mauricio, la idea de separar el archipiélago de Chagos de Mauricio. Aunque el Primer Ministro se mostró favorable a poner "facilidades", indicó que prefería un arrendamiento a largo plazo en lugar de la separación. 
101. El 19 de julio de 1965, el Gobernador de Mauricio recibió instrucciones de la Oficina Colonial de informar al Consejo de Ministros de Mauricio sobre la propuesta de separar constitucionalmente el archipiélago de Chagos de Mauricio. El 30 de julio de 1965, el Gobernador de Mauricio informó a la Oficina Colonial de que el Consejo de Ministros se oponía a la separación debido a la reacción negativa que suscitaría en la población de Mauricio. El Gobernador indicó que el Consejo de Ministros había expresado su preferencia por un arrendamiento a largo plazo de las islas, mientras que el Reino Unido indicó que un arrendamiento no era aceptable.

102. El 3 de septiembre de 1965, Sir Seewoosagur Ramgoolam y Sir Anthony Greenwood, Secretario de Estado del Reino Unido para las Colonias, se reunieron en Londres antes del comienzo de la Cuarta Conferencia Constitucional y acordaro n que el debate sobre la separación y la conferencia constitucional debían mantenerse separados. Sin embargo, parece que ese enfoque se modificó posteriormente para vincular ambas cuestiones en un posible acuerdo global.

103. El 7 de septiembre de 1965, la Cuarta Conferencia Constitucional dio comienzo en Londres y terminó el 24 de septiembre de 1965. Las anteriores conferencias constitucionales se habían celebrado en julio de 1955, febrero de 1957 y junio de 1961. Durante la Cuarta Conferencia Constitucional se mantuvieron varias reuniones privadas sobre asuntos de defensa. La primera reunión, el 13 de septiembre de 1965, contó con la asistencia de Sir Seewoosagur Ramgoolam, Sir Anthony Greenwood y el Sr. John Rennie. En la reunión, el Primer Ministro afirmó que Mauricio prefería un arrendamiento a una separación del archipiélago de Chagos. Después de la reunión, el Secretario de Relaciones Exteriores y el Secretario de Defensa del Reino Unido concluyeron que, si Mauricio no aceptaba la separación, tendrían que "adoptar la recomendación del Ministerio de Relaciones Exteriores y el Ministerio de Defensa de llevar a cabo la 'separación forzosa y el pago de una indemnización a un fondo"'.

104. El 20 de septiembre de 1965, durante una reunión sobre asuntos de defensa presidida por el Secretario de Estado del Reino Unido, el Primer Ministro de Mauricio reiteró que "el Gobierno de Mauricio no estaba interesado en la escisión de las islas y defendería un arrendamiento de 99 años". Como alternativa, el Primer Ministro de Mauricio propuso que el Reino Unido concediera primero la independencia a Mauricio y 
que, posteriormente, permitiera al Gobierno de Mauricio negociar con los Gobiernos del Reino Unido y los Estados Unidos sobre la cuestión de Diego García. Durante esas conversaciones, el Secretario de Estado indicó que un arrendamiento no sería aceptable para los Estados Unidos y que el archipiélago de Chagos tendría que estar disponible sobre la base de su separación.

105. El 22 de septiembre de 1965, Sir Oliver Wright, Secretario Privado del Primer Ministro del Reino Unido, Sir Harold Wilson, preparó una nota que decía lo siguiente:

"Sir Seewoosagur Ramgoolam irá a verlo a usted mañana por la mañana, a las 10.00 horas. El objetivo es atemorizar a Sir Seewoosagur Ramgoolam dándole esperanzas: darle esperanzas de que podría obtener la independencia; atemorizarlo con que podría no conseguirla a menos que se muestre razonable acerca de la separación del archipiélago de Chagos. Adjunto un informe preparado por la Oficina Colonial, con el que el Ministerio de Defensa y el Ministerio de Relaciones Exteriores están, en general, satisfechos. La frase clave del informe es la última de la página tres".

106. La última frase clave mencionada decía lo siguiente:

"El Primer Ministro tal vez desee realizar alguna referencia indirecta al hecho de que el Gobierno de Su Majestad tiene, en el plano jurídico, el derecho a separar Chagos por decreto sin el consentimiento de Mauricio, pero que esta sería una medida grave" (en cursiva en el original).

107. El 23 de septiembre de 1965 tuvieron lugar dos acontecimientos. El primero fue una reunión celebrada por la mañana entre el Primer Ministro Wilson y el Primer Ministro Ramgoolam. Según el informe de Sir Oliver Wright sobre la reunión, el Primer Ministro Wilson le dijo al Primer Ministro Ramgoolam que

“en teoría, existían varias posibilidades. El Primer Ministro y sus colegas podían regresar a Mauricio con la independencia o sin ella. En el aspecto de la defensa, Diego García podía separarse bien por decreto o bien con el consentimiento del Primer Ministro y sus colegas. La mejor solución podía ser la independencia 
y la separación mediante acuerdo, aunque él, por supuesto, no podía comprometer al Secretario Colonial sobre este extremo ".

108. El segundo acontecimiento, ese mismo día, fue una reunión sobre asuntos de defensa en Lancaster House entre el Primer Ministro Ramgoolam, otros tres ministros de Mauricio y el Secretario de Estado del Reino Unido. Al final de esa reunión, el Secretario de Estado del Reino Unido preguntó si los ministros de Mauricio aceptarían la separación del archipiélago de Chagos sobre la base de los compromisos que él recomendaría al Gabinete. Los compromisos asumidos en el acuerdo de Lancaster House, que figuran en el párrafo 22 del acta de la reunión celebrada el 23 de septiembre de 1965, eran los siguientes:

“i) Negociaciones para un acuerdo de defensa entre el Reino Unido y Mauricio;

ii) En caso de independencia, un acuerdo entre los dos Gobiernos en el sentido de que se consultarían entre sí en caso de que surgiera una difícil situación de seguridad interna en Mauricio;

iii) Debería pagarse al Gobierno de Mauricio una indemnización de hasta 3 millones de libras, además de una indemnización directa a los propietarios de tierras y el costo de reasentar a otras personas afectadas en las islas Chagos;

iv) El Gobierno británico interpondría sus buenos oficios con el Gobierno de los Estados Unidos en apoyo de la solicitud de Mauricio de concesiones sobre las importaciones de azúcar y el suministro de trigo y otros productos básicos;

v) Que el Gobierno británico haría todo lo posible por convencer al Gobierno de los Estados Unidos de que utilizase mano de obra y materiales de Mauricio para las obras de construcción en las islas;

vii) Que, si la necesidad de instalaciones en las islas desapareciera, las islas deberían devolverse a Mauricio”.

El Primer Ministro de Mauricio informó al Secretario de Estado para las Colonias de que las propuestas presentadas por el Reino Unido eran aceptables en principio, pero que examinaría la cuestión con sus otros colegas ministeriales. 
109. El 24 de septiembre de 1965, el Gobierno del Reino Unido anunció que estaba a favor de conceder la independencia a Mauricio.

110. El 6 de octubre de 1965, el Secretario de Estado para las Colonias comunicó al Gobernador de Mauricio la aceptación del Reino Unido del siguiente entendimiento adicional solicitado por el Primer Ministro de Mauricio:

i) El Gobierno británico interpondría sus buenos oficios con el Gobierno de los Estados Unidos para velar por que las siguientes instalaciones del archipiélago de Chagos siguieran estando a disposición del Gobierno de Mauricio, en la medida de lo posible:

a) Instalaciones meteorológicas y de navegación;

b) Derechos de pesca;

c) Uso de pistas de aterrizaje para el aterrizaje de emergencia y el repostaje de aviones civiles sin desembarco de pasajeros.

ii) Que el beneficio de cualquier mineral o petróleo descubierto en el archipiélago de Chagos o cerca de él debía revertir al Gobierno de Mauricio.

Este entendimiento adicional se incorporó en el acta final de la reunión celebrada en Lancaster House y pasó a formar parte del acuerdo de Lancaster House.

111. En un documento enviado el 5 de noviembre de 1965 al Primer Ministro del Reino Unido, el Secretario de Estado para las Colonias expresó su preocupación por el hecho de que se pudiera acusar al Reino Unido de "crear una [...] colonia en un período de descolonización y de establecer nuevas bases militares cuando deberíamos estar saliendo de las antiguas". El Ministerio de Relaciones Exteriores señaló también que "las islas elegidas apenas tienen habitantes permanentes".

112. El 5 de noviembre de 1965, el Gobernador de Mauricio informó al Secretario de Estado del Reino Unido de que el Consejo de Ministros de Mauricio "confirmaba el acuerdo para la separación del archipiélago de Chagos”. El Gobernador señaló que el consentimiento se había concedido teniendo en cuenta las condiciones establecidas en el párrafo 22 del acta de la reunión celebrada el 23 de septiembre de 1965 (que contenía el acuerdo de Lancaster House) y que el Consejo de Ministros había formulado un entendimiento adicional. 


\section{Situación de los chagosianos}

113. A principios del siglo XIX, varios cientos de personas fueron trasladadas al archipiélago de Chagos desde Mozambique y Madagascar y esclavizadas para trabajar en las plantaciones de cocoteros propiedad de nacionales británicos que vivían en la isla de Mauricio. En la década de 1830 se puso en libertad a 60.000 personas esclavizadas en Mauricio, incluidas las del archipiélago de Chagos.

114. Tras el Acuerdo de 1966 (véase el párrafo 36), entre 1967 y 1973 se impidió regresar a los habitantes del archipiélago de Chagos que habían abandonado las islas. Los demás habitantes fueron expulsados a la fuerza y se les impidió regresar a las islas (véase el párrafo 43).

115. El 16 de abril de 1971, el Comisionado del Territorio Británico del Océano Índico promulgó el Decreto de Inmigración de 1971, que prohibía a cualquier persona entrar o permanecer en el archipiélago de Chagos sin un permiso. También preveía que el Comisionado dictara una orden para expulsar a dichas personas del archipiélago de Chagos (Chagos Islanders v. Attorney General and BIOT Commissioner (2003) EWHC 2222, párr. 34).

116. En el procedimiento oral, el Reino Unido reiteró que "acepta plenamente que la manera en que los chagosianos fueron expulsados del archipiélago de Chagos, así como la manera en que se los trató posteriormente, fue vergonzosa y equivocada, y lamenta profundamente ese hecho".

117. El 4 de septiembre de 1972, en virtud de un acuerdo concertado entre Mauricio y el Reino Unido, Mauricio aceptó el pago de la suma de 650. 000 libras en cumplimiento completo y definitivo del compromiso contraído por el Reino Unido en 1965 de sufragar los costos del reasentamiento de las personas desplazadas fuera del archipiélago de Chagos. El 24 de marzo de 1973, el Primer Ministro Ramgoolam escribió al Alto Comisionado Británico en Port Louis para acusar recibo de la suma de 650.000 libras, pero hizo hincapié en que el pago no afectaba al acuerdo verbal relativo a los derechos sobre los minerales, la pesca y la prospección alcanzado en Lancaster House el 23 de septiembre de 1965 y estaba sujeto al resto de los compromisos asumidos en Lancaster House, como la devolución de las islas a Mauricio sin indemnización en caso de que ya no existiera la necesidad del uso de las islas por parte del Reino Unido. 
118. En febrero de 1975, el Sr. Michel Vencatessen, antiguo residente del archipiélago de Chagos, interpuso una demanda contra el Gobierno del Reino Unido para exigir una indemnización por los actos de intimidación, privación de libertad y agresión relacionados con su expulsión del archipiélago de Chagos en 1971. En 1982 la reclamación se suspendió por acuerdo de las partes.

119. El 7 de julio de 1982 se concertó un acuerdo entre los Gobiernos de Mauricio y el Reino Unido para el pago por el Reino Unido de la suma de 4 millones de libras a título graciable, sin admisión de responsabilidad por parte del Reino Unido, "como arreglo completo y definitivo de toda reclamación de la índole mencionada en el artículo 2 del presente Acuerdo contra [...] el Reino Unido presentada por o en nombre de los ilois". De conformidad con el segundo párrafo del preámbulo del Acuerdo, el término ilois debe entenderse como las personas que se fueron a Mauricio a su salida o expulsión del archipiélago de Chagos después de noviembre de 1965. El artículo 2 establece lo siguiente:

"Las reclamaciones previstas en el artículo 1 del presente Acuerdo son únicamente reclamaciones presentadas por o en nombre de los ilois derivadas de:

a) Todos los actos, asuntos y acciones llevados a cabo de conformidad con la Orden relativa al Territorio Británico del Océano Índico de 1965, incluido el cierre de las plantaciones del archipiélago de Chagos, la salida o expulsión de las personas que vivían o trabajaban allí, la terminación de sus contratos, su traslado a Mauricio y su reasentamiento allí y la prohibición de que regresen al archipiélago de Chagos (en lo sucesivo, los “acontecimientos"); y

b) Todo incidente, hecho o situación, sea pasado, presente o futuro, producido en el transcurso de los acontecimientos o que sea consecuencia de ellos".

El artículo 4 exige a Mauricio "que obtenga de cada miembro de la comunidad de ilois de Mauricio una renuncia firmada a las reclamaciones".

120. Entre 1983 y 1984, el Reino Unido pagó la suma de aproximadamente 4 millones de libras, que se desembolsó a 1.344 isleños. Como condición para la recogida de los fondos, los isleños debían firmar o estampar la huella dactilar en un formulario renunciando a su derecho a regresar al archipiélago de Chagos. El formulario era un documento 
jurídico de una página, redactado en inglés y sin traducción al criollo. Solo 12 personas se negaron a firmar (Chagos Islanders v. Attorney General and BIOT Commissioner (2003) EWHC 2222, párr. 80).

121. En 1998, un chagosiano, el Sr. Louis Olivier Bancoult, inició un proceso ante los tribunales del Reino Unido cuestionando la validez de la legislación que le denegaba el derecho a residir en el archipiélago de Chagos. El 3 de noviembre de 2000, el Tribunal de División dictó un fallo a su favor en el que se invalidaban las disposiciones pertinentes del Decreto de 1971 (Regina (Bancoult) v. Secretary of State for Foreign and Commonwealth Affairs \& another (No. 1) (2000)). El Gobierno del Reino Unido no interpuso recurso de apelación contra la decisión y derogó el Decreto de 1971 que había prohibido a los chagosianos regresar al archipiélago de Chagos. El Secretario de Estado de Relaciones Exteriores del Reino Unido anunció que el Gobierno del Reino Unido estaba examinando la viabilidad de reasentar a los ilois.

122. El mismo día en que el Tribunal de División dictó el fallo a favor del Sr. Bancoult, el Reino Unido aprobó otro decreto de inmigración aplicable al archipiélago de Chagos, con la excepción de Diego García ( Decreto núm. 4 de 2000), en el que se disponía que las restricciones a la entrada y la residencia en el archipiélago no serían aplicables a los chagosianos, en vista de su relación con las islas Chagos. En su exposición escrita, el Reino Unido afirma que, tras la aprobación de ese Decreto, ninguna persona natural del archipiélago de Chagos volvió a vivir allí a pesar de que no había ningún obstáculo jurídico que le impidiera hacerlo. Sin embargo, no se permitía a esas personas entrar o residir en Diego García.

123. El 6 de diciembre de 2001, el Comité de Derechos Humanos establecido con arreglo al Pacto Internacional de Derechos Civiles y Políticos, al examinar los informes periódicos presentados por el Reino Unido en virtud del artículo 40 de dicho Pacto, tomó nota de "la admisión por el Estado parte del carácter ilegal de la prohibición del retorno de los ilois que habían abandonado el territorio o sido trasladados de él". Recomendó que, "en la medida de lo posible, el Estado parte debe tratar de hacer viable el ejercicio del derecho de los ilois a regresar a su territorio".

124. En junio de 2002 se efectuó un estudio de viabilidad encargado por la Administración del Territorio Británico del Océano Índico en relación con el archipiélago de Chagos, que se llevó a cabo en respuesta 
a una solicitud formulada por los antiguos habitantes del archipiélago de Chagos para que se les permitiera regresar y vivir en el archipiélago. El estudio indicó que, si bien podría ser factible reasentar a los isleños a corto plazo, el costo de mantener una ocupación a largo plaz o podría ser prohibitivo. Incluso a corto plazo, los fenómenos naturales como las inundaciones periódicas causadas por tormentas y la actividad sísmica podrían hacer difícil la vida para una población reasentada. En 2004 , el Reino Unido aprobó la Orden relativa a la Constitución del Territorio Británico del Océano Índico de 2004 y la Orden sobre Inmigración al Territorio Británico del Océano Índico de 2004, en las que se estableció que nadie tenía derecho a residir en el Territorio Británico del Océano Índico ni derecho a entrar y permanecer allí sin autorización.

125. En 2004, el Sr. Bancoult impugnó la validez de la Orden relativa a la Constitución del Territorio Británico del Océano Índico de 2004 y la Orden sobre Inmigración al Territorio Británico del Océano Índico de 2004 ante los tribunales del Reino Unido, y sus pretensiones fueron acogidas por el Tribunal Superior. El Secretario de Estado de Relaciones Exteriores y Asuntos del Commonwealth presentó un recurso contra la decisión del Tribunal Superior. El Tribunal de Apelaciones confirmó la decisión del Tribunal Superior de que las Órdenes no eran válidas fundándose en que su contenido y las circunstancias de su aprobación constituían un abuso de poder por el Gobierno del Reino Unido ( Regina (Bancoult) v. Secretary of State for Foreign and Commonwealth Affairs (No. 2) (2007)).

126. El 30 de julio de 2008, el Comité de Derechos Humanos, al examinar otro informe periódico presentado por el Reino Unido, tomó nota de la citada decisión del Tribunal de Apelaciones. Sobre la base del artículo 12 del Pacto Internacional de Derechos Civiles y Políticos, el Comité formuló las siguientes recomendaciones:

"El Estado parte debe velar por que los naturales de las islas Chagos puedan ejercer el derecho de regresar a su territorio e indicar qué medidas se han tomado al respecto. Debe considerar la posibilidad de indemnizarlos por haber denegado ese derecho durante un período prolongado".

127. El Secretario de Estado de Relaciones Exteriores y Asuntos del Commonwealth recurrió la decisión del Tribunal de Apelaciones (véase el párrafo 125) que acogía la impugnación por el Sr. Bancoult de la validez de la Orden relativa a la Constitución del Territorio Británico del Océano 
Índico de 2004. El 22 de octubre de 2008, la Cámara de los Lores acogió el recurso interpuesto por el Secretario de Estado de Relaciones Exteriores y Asuntos del Commonwealth.

128. El 11 de diciembre de 2012, el Tribunal Europeo de Derechos Humanos, en el asunto Naturales de las islas Chagos c. Reino Unido, declaró inadmisible una demanda presentada por un grupo de 1.786 chagosianos contra el Reino Unido por la violación de sus derechos reconocidos en el Convenio Europeo de Derechos Humanos. Uno de los fundamentos de la decisión fue que las reclamaciones de los demandantes habían sido resueltas mediante el Acuerdo de 1982 entre Mauricio y el Reino Unido.

129. El 20 de diciembre de 2012, el Reino Unido anunció una revisión de su política de reasentamiento de los chagosianos que habían sido desplazados a la fuerza o a los que se había impedido regresar al archipiélago de Chagos. La Administración del Territorio Británico del Océano Índico encargó un segundo estudio de viabilidad, realizado entre 2014 y 2015, para analizar las diferentes opciones de reasentamiento en el archipiélago de Chagos. El estudio de viabilidad concluyó que el reasentamiento era posible, pese a que entrañaría importantes dificultades, como unos costos elevados y muy inciertos y pasivos a largo plazo para el contribuyente del Reino Unido. Posteriormente, el 16 de noviembre de 2016, el Reino Unido renunció a la idea del reasentamiento "tomando en cuenta la viabilidad, los intereses en materia de defensa y seguridad y el costo para el contribuyente británico".

130. El 8 de febrero de 2018, el Tribunal Supremo del Reino Unido pronunció su sentencia en la causa Regina (on the application of Bancoult No. 3) v. Secretary of State for Foreign and Commonwealth Affairs (2018), en la que el Sr. Bancoult actuaba en nombre de un grupo de chagosianos que habían sido desplazados a la fuerza del archipiélago. En el proceso, el Sr. Bancoult cuestionó la declaración de una zona marina protegida por el Reino Unido alrededor del archipiélago de Chagos y afirmó que dicha zona se había establecido indebidamente con el propósito de imposibilitar el reasentamiento de los chagosianos en el archipiélago. Sostuvo que este hecho se ponía de manifiesto en un cable diplomático enviado por la embajada de los Estados Unidos en Londres a los departamentos del Gobierno de los Estados Unidos en Washington, a elementos de su estructura de mando militar y a su embajada en Port Louis (Mauricio). El cable registraba una reunión celebrada en 2009 en la que funcionarios 
de los Estados Unidos y el Reino Unido analizaban las razones para el establecimiento de la zona marina protegida. Posteriormente, el cable se filtró y publicó en dos periódicos nacionales. Cuando se le solicitó en la apelación que decidiera sobre la admisibilidad de ese cable, el Tribunal Supremo entendió que era admisible. No obstante, desestimó el recurso por otros motivos.

131. Hasta la fecha, los chagosianos siguen dispersos en varios países, entre ellos el Reino Unido, Mauricio y Seychelles. La legislación del Reino Unido y las decisiones judiciales de ese país no les permiten regresar al archipiélago de Chagos.

\section{Cuestiones planteadas a la Corte por la Asamblea General}

132. Habiendo examinado los antecedentes de hecho de la presente solicitud de opinión consultiva, la Corte pasará a examinar seguidamente las dos cuestiones planteadas por la Asamblea General:

Cuestión a): “¿Se completó con arreglo a derecho el proceso de descolonización de Mauricio cuando Mauricio obtuvo la independencia en 1968, después de la separación del archipiélago de Chagos de Mauricio y teniendo en cuenta el derecho internacional, incluidas las obligaciones recogidas en las resoluciones de la Asamblea General 1514 (XV), de 14 de diciembre de 1960, 2066 (XX), de 16 de diciembre de 1965, 2232 (XXI), de 20 de diciembre de 1966, y 2357 (XXII), de 19 de diciembre de 1967?”.

Cuestión b): “¿Cuáles son las consecuencias en virtud del derecho internacional, incluidas las obligaciones reflejadas en las resoluciones mencionadas, que se derivan de que el Reino Unido de Gran Bretaña e Irlanda del Norte siga administrando el archipiélago de Chagos, entre otras cosas respecto a que Mauricio no pueda aplicar un programa para reasentar en el archipiélago de Chagos a sus nacionales, en particular los originarios del archipiélago de Chagos?".

133. Algunos participantes solicitan a la Corte que reformule ambas cuestiones o que las interprete de manera restrictiva. En particular, cuestionan la suposición de que las resoluciones mencionadas en la cuestión a) 
crean obligaciones internacionales para el Reino Unido, lo cual prejuzgaría la respuesta que se solicita a la Corte. También sostienen que las cuestiones jurídicas se refieren en realidad al asunto de la soberanía sobre el archipiélago de Chagos, que es objeto de una controversia bilateral entre Mauricio y el Reino Unido.

134. Un participante afirma que la solicitud de la Asamblea General, que no se refiere expresamente a las consecuencias jurídicas que tiene para los Estados que el Reino Unido siga administrando el archipiélago de Chagos, debería interpretarse de manera que la opinión consultiva se limite a las funciones de las Naciones Unidas, con exclusión de todas las cuestiones que conciernen a los Estados, en particular Mauricio y el Reino Unido.

135. La Corte recuerda que puede apartarse de la redacción de la cuestión planteada cuando esta no esté debidamente formulada (Interpretación del Acuerdo entre Grecia y Turquia de $1^{\circ}$ de diciembre de 1926 (Protocolo Definitivo, artículo IV), opinión consultiva, 1928, P.C.I.J., Serie B, núm. 16) o no refleje las "cuestiones jurídicas realmente en cuestión” (Interpretación del Acuerdo de 25 de marzo de 1951 entre la OMS y Egipto, opinión consultiva, I.C.J. Reports 1980, pág. 89, párr. 35). De igual modo, cuando la cuestión sea ambigua o vaga, la Corte puede aclararla antes de dar su opinión (Petición de revisión del fallo núm. 273 del Tribunal Administrativo de las Naciones Unidas, opinión consultiva, I.C.J. Reports 1982, pág. 348, párr. 46). Pese a que, en circunstancias excepcionales, la Corte puede reformular las cuestiones que se le plantean para que emita una opinión consultiva, solamente lo hace para garantizar una respuesta "basada en derecho" (Caso relativo al Sábara Occidental, opinión consultiva, I.C.J. Reports 1975, pág. 18, párr. 15).

136. La Corte considera que, en el presente procedimiento, no necesita reformular las cuestiones que se le han planteado para que emita una opinión consultiva. En efecto, la primera cuestión se refiere a si el proceso de descolonización de Mauricio se completó con arreglo a derecho en 1968, teniendo en cuenta el derecho internacional, tras la separación del archipiélago de Chagos de su territorio en 1965. El hecho de que la Asamblea General mencione determinadas resoluciones que aprobó durante ese período no prejuzga, en opinión de la Corte, el contenido o alcance jurídico de estas. En la cuestión a), la Asamblea General pide a la Corte que examine determinados hechos que ocurrieron entre 1965 y 1968 y que se inscriben en el marco del proceso de descolonización de Mauricio 
como Territorio No Autónomo. No sometió a la Corte una controversia bilateral sobre la soberanía que pudiera existir entre el Reino Unido y Mauricio. En la cuestión b), que está claramente vinculada a la cuestión a), se pide a la Corte que declare cuáles son las consecuencias, en virtud del derecho internacional, de que el Reino Unido siga administrando el archipiélago de Chagos. Al referirse de este modo al derecho internacional, la Asamblea General tenía en mente necesariamente las consecuencias para los sujetos de ese derecho, incluidos los Estados.

137. Corresponde a la Corte declarar cuál es el derecho aplicable a la situación de hecho expuesta por la Asamblea General en su solicitud de opinión consultiva. Por tanto, no es necesario que interprete de manera restrictiva las cuestiones planteadas por la Asamblea General. Cuando la Corte determina el derecho aplicable en el ejercicio de su función consultiva, presta su ayuda a la Asamblea General para la solución de un problema al que esta se enfrenta (Caso relativo al Sáhara Occidental, opinión consultiva, I.C.J. Reports 1975, pág. 21, párr. 23). Al emitir su opinión consultiva, la Corte no interfiere con el ejercicio de las funciones que corresponden a la Asamblea General.

138. La Corte examinará ahora la primera cuestión planteada por la Asamblea General, a saber, si el proceso de descolonización de Mauricio se completó con arreglo a derecho y teniendo en cuenta el derecho internacional.

\section{A. Cuestión de si el proceso de descolonización de Mauricio se completó con arreglo a derecho y teniendo en cuenta el derecho internacional (cuestión a))}

139. A fin de pronunciarse sobre si el proceso de descolonización de Mauricio se completó con arreglo a derecho y teniendo en cuenta el derecho internacional, la Corte determinará, en primer lugar, el período de tiempo pertinente para determinar el derecho internacional aplicable y, en segundo lugar, el contenido de ese derecho. Además, dado que la Asamblea General menciona algunas de las resoluciones que ha aprobado, la Corte, al determinar las obligaciones recogidas en estas resolucione s, habrá de examinar las funciones de la Asamblea General durante el proceso de descolonización. 


\section{Período de tiempo pertinente para determinar el derecho internacional aplicable}

140. En la cuestión a), la Asamblea General sitúa el proceso de descolonización de Mauricio en el período comprendido entre la separación del archipiélago de Chagos de su territorio en 1965 y su independencia en 1968. Por consiguiente, la Corte debe determinar el derecho internacional aplicable a ese proceso por referencia a dicho período.

141. Varios participantes afirman que el derecho internacional no queda congelado en la fecha en que se adoptan las primeras medidas con miras a hacer efectivo del derecho a la libre determinación respecto de un territorio.

142. La Corte opina que, si bien la determinación del derecho aplicable debe centrarse en el período comprendido entre 1965 y 1968, esto no impide, en particular cuando se trata de normas consuetudinarias, examinar la evolución del derecho a la libre determinación desde la aprobación de la Carta de las Naciones Unidas y de la resolución 1514 (XV), de 14 de diciembre de 1960, titulada "Declaración sobre la Concesión de la Independencia a los Países y Pueblos Coloniales”. En efecto, la práctica de los Estados y la opinio iuris, es decir, la aceptación de esa práctica como derecho (Artículo 38 del Estatuto de la Corte), se consolidan y se confirman gradualmente a lo largo del tiempo.

143. La Corte también puede basarse en instrumentos jurídicos posteriores al período en cuestión cuando dichos instrumentos confirmen o interpreten normas o principios preexistentes.

\section{Derecho internacional aplicable}

144. La Corte deberá determinar la naturaleza, el contenido y el alcance del derecho a la libre determinación aplicable al proceso de descolonización de Mauricio, Territorio No Autónomo reconocido como tal, a partir de 1946, tanto en la práctica de las Naciones Unidas como por la propia Potencia administradora. La Corte es consciente de que el derecho a la libre determinación, como derecho humano fundamental, tiene un ámbito de aplicación amplio. Sin embargo, para responder a la cuestión planteada por la Asamblea General, la Corte se limitará, en esta 
opinión consultiva, a analizar el derecho a la libre determinación en el contexto de la descolonización.

145. Los participantes en el procedimiento consultivo han adoptado posiciones opuestas en relación con el carácter consuetudinario del derecho a la libre determinación, su contenido y la forma en que se ejerció entre 1965 y 1968. Algunos participantes afirman que el derecho a la libre determinación estaba firmemente establecido en el derecho internacional consuetudinario en el período en cuestión. Otros sostienen que el derecho a la libre determinación no era parte integrante del derecho internacional consuetudinario durante dicho período.

146. La Corte comenzará por recordar que "el respeto al principio de la igualdad de derechos y al de la libre determinación de los pueblos" es uno de los propósitos de las Naciones Unidas (Artículo 1, párrafo 2, de la Carta). Ese propósito se refiere, en particular, a la "Declaración relativa a los Territorios No Autónomos" (Capítulo XI de la Carta), dado que los "Miembros de las Naciones Unidas que tengan o asuman la responsabilidad de administrar territorios cuyos pueblos no hayan alcanzado todavía la plenitud del gobierno propio" están obligados a "desarrollar el gobierno propio" de esos pueblos (Artículo 73 de la Carta).

147. En opinión de la Corte, de ello se desprende que el régimen jurídico de los Territorios No Autónomos previsto en el Capítulo XI de la Carta se basaba en el desarrollo progresivo de sus instituciones a fin de llevar a las poblaciones afectadas a ejercer su derecho a la libre determinación.

148. Tras convertir el respeto al principio de la igualdad de derechos y al de la libre determinación de los pueblos en uno de los propósitos de las Naciones Unidas, la Carta incluyó disposiciones que permitirían que los Territorios No Autónomos acabaran gobernándose por sí mismos. En este contexto, la Corte debe determinar cuándo se cristalizó el derecho a la libre determinación como norma consuetudinaria vinculante para todos los Estados.

149. La costumbre se constituye a través de una "práctica generalmente aceptada como derecho" (Artículo 38 del Estatuto de la Corte). La Corte ha destacado que ambos elementos, a saber, la práctica general y la opinio iuris, que son elementos constitutivos de la costumbre internacional, están estrechamente relacionados: 
"Los actos en cuestión no solo deben constituir una práctica establecida, sino que, además, deben ser de tal naturaleza o ejecutarse de tal modo que demuestren la convicción de que dicha práctica es obligatoria en virtud de la existencia de una norma de derecho que la impone. La necesidad de esa convicción, es decir, la existencia de un elemento subjetivo, está implícita en la idea misma de la opinio iuris sive necessitatis. Por consiguiente, los Estados interesados deben sentir que se están ajustando a lo que constituye una obligación jurídica. La frecuencia, o incluso el carácter habitual de los actos, no es suficiente por sí misma" (Plataforma continental del mar del Norte, fallo, I.C.J. Reports 1969, pág. 44, párr. 77).

150. La aprobación de la resolución 1514 (XV), de 14 de diciembre de 1960, constituye un momento decisivo en la consolidación de la práctica de los Estados en materia de descolonización. Antes de esa resolución, la Asamblea General había afirmado en varias ocasiones el derecho a la libre determinación (resoluciones 637 (VII), de 16 de diciembre de 1952, 738 (VIII), de 28 de noviembre de 1953, y 1188 (XII), de 11 de diciembre de 1957) y varios Territorios No Autónomos habían accedido a la independencia. La resolución 1514 (XV) de la Asamblea General aclara el contenido y el alcance del derecho a la libre determinación. La Corte observa que el proceso de descolonización se aceleró en 1960, con la obtención de la independencia por parte de 18 países, 17 de ellos africanos. Durante la década de 1960, los pueblos de otros 28 Territorios No Autónomos ejercieron su derecho a la libre determinación y lograron la independencia. En opinión de la Corte, existe una clara relación entre la resolución 1514 (XV) y el proceso de descolonización después de su aprobación.

151. La Corte ha observado que:

"las resoluciones de la Asamblea General, aunque no son vinculantes, pueden a veces tener valor normativo. En ciertas circunstancias pueden proporcionar pruebas importantes para determinar la existencia de una norma o la aparición de una opinio iuris. Para saber si una determinada resolución de la Asamblea General cumple ese recaudo, hay que examinar su contenido y las condiciones en que se aprobó; también hay que ver si existe una opinio iuris en cuanto a su carácter normativo" (Legalidad de 
la amenaza o el empleo de armas nucleares, opinión consultiva, I.C.J. Reports 1996 (I), págs. 254 y 255, párr. 70).

152. La Corte considera que, si bien la resolución 1514 (XV) es formalmente una recomendación, tiene carácter declaratorio en lo relativo al derecho a la libre determinación como norma consuetudinaria, habida cuenta de su contenido y de las condiciones de su aprobación. La resolución se aprobó por 89 votos y 9 abstenciones. Ninguno de los Estados que participaron en la votación cuestionó la existencia del derecho de los pueblos a la libre determinación. Algunos Estados justificaron su abstención sobre la base del tiempo necesario para dar plena efectividad a ese derecho.

153. La redacción utilizada en la resolución 1514 (XV) tiene carácter normativo en la medida en que en ella se afirma que "todos los pueblos tienen el derecho de libre determinación". Su preámbulo proclama "la necesidad de poner fin rápida e incondicionalmente al colonialismo en todas sus formas y manifestaciones" y su párrafo primero declara que "la sujeción de pueblos a una subyugación, dominación y explotación extranjeras constituye una denegación de los derechos humanos fundamentales [y] es contraria a la Carta de las Naciones Unidas".

La resolución establece además que "en los Territorios en Fideicomiso y No Autónomos y en todos los demás territorios que no han logrado aún su independencia deberán tomarse inmediatamente medidas para traspasar todos los poderes a los pueblos de esos territorios, sin condiciones ni reservas, en conformidad con su voluntad y sus deseos libremente expresados". A fin de evitar el desmembramiento de los Territorios No Autónomos, el párrafo 6 de la resolución 1514 (XV) dispone que:

"Todo intento encaminado a quebrantar total o parcialmente la unidad nacional y la integridad territorial de un país es incompatible con los propósitos y principios de la Carta de las Naciones Unidas".

154. El artículo 1, común al Pacto Internacional de Derechos Civiles y Políticos y al Pacto Internacional de Derechos Económicos, Sociales y Culturales, aprobados el 16 de diciembre de 1966 mediante la resolución 2200 A (XXI) de la Asamblea General, reafirma el derecho de todos los pueblos a la libre determinación y dispone, entre otras cosas, que: 
"Los Estados partes en el presente Pacto, incluso los que tienen la responsabilidad de administrar Territorios No Autónomos y Territorios en Fideicomiso, promoverán el ejercicio del derecho de libre determinación y respetarán este derecho de conformidad con las disposiciones de la Carta de las Naciones Unidas".

155. El carácter y el alcance del derecho a la libre determinación de los pueblos, incluido el respeto a "la unidad nacional y la integridad territorial de un Estado o país", se reiteraron en la Declaración sobre los Principios de Derecho Internacional referentes a las Relaciones de Amistad y a la Cooperación entre los Estados de conformidad con la Carta de las Naciones Unidas. Esta Declaración figura en el anexo de la resolución 2625 (XXV) de la Asamblea General, que fue aprobada por consenso en 1970. Al reconocer el derecho a la libre determinación como uno de los “principios básicos del derecho internacional”, la Declaración confirmó su carácter normativo en virtud del derecho internacional consuetudinario.

156. Los medios para hacer efectivo el derecho a la libre determinación en un Territorio No Autónomo, descrito como territorio que está "separado geográficamente del país que lo administra y es distinto de este en sus aspectos étnicos o culturales", figuran en el Principio VI de la resolución 1541 (XV) de la Asamblea General, aprobada el 15 de diciembre de 1960:

"Puede considerarse que un Territorio No Autónomo ha alcanzado la plenitud del gobierno propio:

a) Cuando pasa a ser un Estado independiente y soberano;

b) Cuando establece una libre asociación con un Estado independiente; o

c) Cuando se integra a un Estado independiente”.

157. La Corte recuerda que, si bien el ejercicio de la libre determinación puede lograrse a través de una de las opciones previstas en la resolución 1541 (XV), ese ejercicio debe ser la expresión libre y auténtica de la voluntad del pueblo de que se trate. Sin embargo, "el derecho a la libre determinación deja a la Asamblea General cierto grado de discreción con respecto a la forma y los procedimientos que hay que adoptar para 
ejecutar ese derecho" (Caso relativo al Sáhara Occidental, opinión consultiva, I.C.J. Reports 1975, pág. 36, párr. 71).

158. El derecho a la libre determinación en virtud del derecho internacional consuetudinario no impone un mecanismo específico para su ejercicio efectivo en todos los casos, como ha observado la Corte:

"La validez del principio de la libre determinación, definido como la necesidad de tomar en consideración la voluntad libremente expresada de los pueblos, no se ve afectada por el hecho de que, en algunos casos, la Asamblea General haya prescindido del requisito de consultar a los habitantes de un territorio determinado. Esos casos se basaban en la consideración de que una determinada población no constituía un 'pueblo' con derecho a la libre determinación o en la convicción de que era totalmente innecesario efectuar una consulta, en atención a la existencia de circunstancias especiales" (Caso relativo al Sábara Occidental, opinión consultiva, I.C.J. Reports 1975, pág. 33, párr. 59).

159. Algunos participantes argumentan que el carácter consuetudinario del derecho a la libre determinación no entraña la obligación de hacer efectivo ese derecho dentro de las fronteras del Territorio No Autónomo.

160. La Corte recuerda que el derecho a la libre determinación del pueblo de que se trate se define por referencia a la totalidad de un Territorio No Autónomo, como se indica en el mencionado párrafo 6 de la resolución 1514 (XV) (véase el párrafo 153). Tanto la práctica de los Estados como la opinio iuris del período pertinente confirman el carácter consuetudinario del derecho a la integridad territorial de un Territorio No Autónomo como corolario del derecho a la libre determinación. No se ha señalado a la atención de la Corte ningún ejemplo en el que, tras la aprobación de la resolución 1514 (XV), la Asamblea General o cualquier otro órgano de las Naciones Unidas hayan considerado lícita la separación por la Potencia administradora de parte de un Territorio No Autónomo a fin de mantenerlo bajo su dominación colonial. Los Estados han insistido sistemáticamente en que el respeto de la integridad territorial de un Territorio No Autónomo es un elemento fundamental del ejercicio del derecho a la libre determinación en virtud del derecho internacional. La Corte considera que los pueblos de Territorios No Autónomos tienen derecho a ejercer su derecho a la libre determinación en relación con el conjunto de su territorio, cuya integridad debe ser respetada por la Poten- 
cia administradora. De ello se desprende que cualquier separación por la Potencia administradora de una parte de un Territorio No Autónomo, a menos que se base en la voluntad auténtica y libremente expresada del pueblo del Territorio en cuestión, es contraria al derecho a la libre determinación.

161. En opinión de la Corte, el derecho a la libre determinación constituye el derecho internacional aplicable durante el período en cuestión, a saber, el comprendido entre 1965 y 1968. La Corte señaló en su opinión consultiva sobre Namibia la consolidación de ese derecho:

"El desarrollo posterior del derecho internacional en relación con los Territorios No Autónomos, consagrado en la Carta de las Naciones Unidas, hizo aplicable a todos ellos el principio de la libre determinación" (Consecuencias jurídicas que tiene para los Estados la continuación de la presencia de Sudáfrica en Namibia (África Sudoccidental), no obstante lo dispuesto en la resolución 276 (1970) del Consejo de Seguridad, opinión consultiva, I.C.J. Reports 1971, pág. 31, párr. 52).

162. La Corte pasará ahora a examinar las funciones de la Asamblea General durante el proceso de descolonización.

\section{Funciones de la Asamblea General con respecto a la descolonización}

163. La Asamblea General ha desempeñado un papel decisivo en la labor de las Naciones Unidas en materia de descolonización, en particular desde la aprobación de la resolución 1514 (XV). Ha supervisado el cumplimiento de las obligaciones de los Estados Miembros a este respecto previstas en el Capítulo XI de la Carta y derivadas de la práctica que se ha desarrollado dentro de la Organización.

164. En este contexto, en la cuestión a) se pide a la Corte que examine, al analizar el derecho internacional aplicable al proceso de descolonización de Mauricio, las obligaciones recogidas en las resoluciones de la Asamblea General 2066 (XX), de 16 de diciembre de 1965, 2232 (XXI), de 20 de diciembre de 1966, y 2357 (XXII), de 19 de diciembre de 1967.

165. En su resolución 2066 (XX), de 16 de diciembre de 1965, titulada "Cuestión de la isla Mauricio", la Asamblea General, tras advertir "con 
profunda inquietud que toda medida adoptada por la Potencia administradora para separar ciertas islas del Territorio de la Isla Mauricio a fin de establecer en ellas una base militar constituiría una violación de la Declaración y, en particular, del párrafo 6 de la misma", invita "a la Potencia administradora a no adoptar ninguna medida que pudiera desmembrar el Territorio de la Isla Mauricio y violar su integridad territorial ".

166. En sus resoluciones 2232 (XXI) y 2357 (XXII), que son más generales y hacen referencia a la situación en varios Territorios No Autónomos, la Asamblea General:

"reitera su declaración en el sentido de que todo intento encaminado a quebrantar total o parcialmente la unidad nacional y la integridad territorial de los territorios coloniales y a establecer bases e instalaciones militares en esos territorios es incompatible con los propósitos y principios de la Carta de las Naciones Unidas y con la resolución 1514 (XV) de la Asamblea General".

167. En opinión de la Corte, al invitar al Reino Unido a que cumpliera con sus obligaciones internacionales durante el proceso de descolonización de Mauricio, la Asamblea General actuó en el marco de la Carta y dentro del ámbito de las funciones que se le asignaron para vigilar la aplicación del derecho a la libre determinación. La Asamblea General asumió esas funciones a fin de supervisar el cumplimiento de las obligaciones impuestas a las Potencias administradoras en virtud de la Carta. Así, estableció un comité especial encargado de examinar los factores que le permitirían decidir "si un territorio está o no en la categoría de territorio cuyo pueblo no ha alcanzado todavía la plenitud del gobierno propio" (resolución 334 (IV), de 2 de diciembre de 1949). La práctica reiterada de la Asamblea General ha sido aprobar resoluciones para pronunciarse sobre la situación concreta de todo Territorio No Autónomo. Por tanto, inmediatamente después de aprobar la resolución 1514 (XV), estableció el Comité de los Veinticuatro, encargado de supervisar la aplicación de esa resolución y de formular sugerencias y recomendaciones al respecto (resolución 1654 (XVI), de 27 de noviembre de 1961). La Asamblea General también supervisa los medios mediante los cuales se expresa la voluntad libre y auténtica del pueblo de un Territorio No Autónomo, entre otros la formulación de las preguntas sometidas a consulta popular.

168. La Asamblea General ha exhortado sistemáticamente a las Potencias administradoras a que respeten la integridad territorial de los Territorios 
No Autónomos, en particular tras la aprobación de la resolución 1514 (XV), de 14 de diciembre de 1960 (véanse, por ejemplo, las resoluciones de la Asamblea General 2023 (XX), de 5 de noviembre de 1965, y 2183 (XXI), de 12 de diciembre de 1966 (Cuestión de Adén); 3161 (XXVIII), de 14 de diciembre de 1973, y 3291 (XXIX), de 13 de diciembre de 1974 (Cuestión del archipiélago de las Comoras); y 34/91, de 12 de diciembre de 1979 (Cuestión de las islas Gloriosas, Juan de Nova, Europa y Bassas da India)).

169. La Corte pasará ahora a examinar las circunstancias relativas a la separación del archipiélago de Chagos de Mauricio y a determinar si se llevó a cabo de conformidad con el derecho internacional.

\section{Aplicación en el presente procedimiento}

170. Es necesario comenzar recordando la condición jurídica de Mauricio antes de su independencia. Tras la concertación del Tratado de París de 1814, la "isla de Mauricio y las dependencias de Mauricio", incluido el archipiélago de Chagos, fueron administradas sin interrupción por el Reino Unido. De esta forma, la totalidad de Mauricio, incluidas sus dependencias, pasó a figurar en la lista de Territorios No Autónomos elaborada por la Asamblea General (resolución 66 (I), de 14 de diciembre de 1946). Sobre esta base, el Reino Unido proporcionó periódicamente a la Asamblea General información sobre las condiciones vigentes en ese territorio, de conformidad con lo dispuesto en el Artículo 73 de la Carta. Por consiguiente, en el momento de su separación de Mauricio en 1965, el archipiélago de Chagos era claramente parte integrante de ese Territorio No Autónomo.

171. En el acuerdo de Lancaster House, de 23 de septiembre de 1965, el Primer Ministro y otros representantes de Mauricio, que aún se encontraba bajo la autoridad del Reino Unido como Potencia administradora, aceptaron en principio la separación del archipiélago de Chagos del territorio de Mauricio. Ese consentimiento se concedió a condición de que el archipiélago no pudiera ser cedido a ningún tercero y se devolviera a Mauricio en una fecha posterior, condición aceptada en aquel momento por el Reino Unido.

172. La Corte observa que, cuando el Consejo de Ministros aceptó en principio la separación del archipiélago de Chagos de Mauricio, este 
último se encontraba, como colonia, bajo la autoridad del Reino Unido. Como observó en su momento el Comité de los Veinticuatro, "la Constitución vigente en la isla Mauricio [...] no permit[e] a los representantes del pueblo ejercer auténticos poderes legislativos ni ejecutivos, y [...] la autoridad está casi totalmente concentrada en manos del Gobierno del Reino Unido y sus representantes" (documento A/5800/Rev.1 de las Naciones Unidas (1964-1965), pág. 382, párr. 154). En opinión de la Corte, no es posible hablar de un acuerdo internacional cuando una de las partes en él, Mauricio, que cedió presuntamente el territorio al Reino Unido, se encontraba bajo la autoridad de este último. La Corte opina que, en una situación en que una parte de un Territorio No Autónomo es separada para crear una nueva colonia, la cuestión del consentimiento debe ser objeto de un riguroso examen. Habiendo examinado las circunstancias en las que el Consejo de Ministros de la colonia de Mauricio aceptó en principio la separación del archipiélago de Chagos sobre la base del acuerdo de Lancaster House, la Corte considera que esa separación no se basó en la expresión libre y auténtica de la voluntad del pueblo en cuestión.

173. En su resolución 2066 (XX), de 16 de diciembre de 1965, aprobada pocas semanas después de la separación del archipiélago de Chagos, la Asamblea General estimó oportuno recordar la obligación del Reino Unido, como Potencia administradora, de respetar la integridad territorial de Mauricio. La Corte considera que las obligaciones derivadas del derecho internacional y recogidas en las resoluciones aprobadas por la Asamblea General durante el proceso de descolonización de Mauricio exigen que el Reino Unido, en su calidad de Potencia administradora, respete la integridad territorial de ese país, incluido el archipiélago de Chagos.

174. La Corte concluye que, como resultado de la separación ilícita del archipiélago de Chagos y su incorporación a una nueva colonia, conocida como Territorio Británico del Océano Índico, el proceso de descolonización de Mauricio no se completó con arreglo a derecho cuando Mauricio accedió a la independencia en 1968.

\section{B. Consecuencias en virtud del derecho internacional que se derivan de que el Reino Unido siga administrando el archipiélago de Chagos (cuestión $b$ ))}


175. Tras haber determinado que el proceso de descolonización de Mauricio no se completó con arreglo a derecho en 1968, la Corte debe ahora examinar las consecuencias, en virtud del derecho internacional, que se derivan de que el Reino Unido siga administrando el archipiélago de Chagos (cuestión b)). La Corte responderá a esta cuestión, redactada en tiempo presente, sobre la base del derecho internacional aplicable en el momento en que se emita su opinión.

176. Varios participantes en el proceso ante la Corte argumentan que el hecho de que el Reino Unido siga administrando el archipiélago de Chagos tiene consecuencias en virtud del derecho internacional, no solo para el propio Reino Unido, sino también para otros Estados y organizaciones internacionales. Entre esas consecuencias figura la obligación de que el Reino Unido ponga fin de inmediato a su administración del archipiélago de Chagos y lo devuelva a Mauricio. Algunos participantes van más allá y abogan por que el Reino Unido repare el perjuicio sufrido por Mauricio. Otros consideran que la antigua Potencia administradora debe cooperar con Mauricio en lo relativo al reasentamiento en el archipiélago de Chagos de los nacionales de este último, en particular los originarios del archipiélago de Chagos.

Por el contrario, un participante sostiene que la única consecuencia para el Reino Unido en virtud del derecho internacional se refiere a la retrocesión del archipiélago de Chagos cuando ya no sea necesario para los fines de defensa de ese Estado. Por último, algunos participantes estiman que el plazo para completar el proceso de descolonización de Mauricio es una cuestión en torno a la cual Mauricio y el Reino Unido deben entablar negociaciones bilaterales.

En cuanto a las consecuencias para terceros Estados, algunos participantes sostienen que esos Estados tienen la obligación de no reconocer la situación ilícita resultante de que el Reino Unido siga administrando el archipiélago de Chagos y de no prestar asistencia para mantenerla.

177. De la conclusión de la Corte de que la descolonización de Mauricio no se llevó a cabo de manera compatible con el derecho de los pueblos a la libre determinación se deduce que el hecho de que el Reino Unido siga administrando el archipiélago de Chagos constituye un hecho ilícito que entraña la responsabilidad internacional de ese Estado (véanse Canal de 
Corfú (Reino Unido c. Albania) (fondo), fallo, I.C.J. Reports 1949, pág. 23, y Proyecto Gabč̌kovo-Nagymaros (Hungría/Eslovaquia), fallo, I.C.J. Reports 1997, pág. 38, párr. 47; véase también el artículo 1 de los Artículos sobre la Responsabilidad del Estado por Hechos Internacionalmente Ilícitos). Se trata de un hecho ilícito de carácter continuo que surgió como resultado de la separación del archipiélago de Chagos de Mauricio.

178. En consecuencia, el Reino Unido tiene la obligación de poner fin a su administración del archipiélago de Chagos con la mayor rapidez posible, lo que permitirá a Mauricio completar el proceso de descolonización de su territorio de manera compatible con el derecho de los pueblos a la libre determinación.

179. Corresponde a la Asamblea General de las Naciones Unidas, en el ejercicio de sus funciones con respecto a la descolonización, determinar las modalidades necesarias para garantizar la conclusión del proceso de descolonización de Mauricio . Como ha señalado en anteriores ocasiones, no corresponde a la Corte "determinar qué medidas podría querer tomar la Asamblea General después de recibir la opinión de la Corte o qué efecto podría tener esa opinión en relación con esas medidas" (Conformidad con el derecho internacional de la declaración unilateral de independencia relativa a Kosovo, opinión consultiva, I.C.J. Reports 2010 (II), pág. 421, párr. 44).

180. Dado que el respeto del derecho a la libre determinación es una obligación erga omnes, todos los Estados tienen un interés jurídico en la protección de ese derecho (véase Timor Oriental (Portugal c. Australia), fallo, I.C.J. Reports 1995, pág. 102, párr. 29; véase también Barcelona Traction, Light and Power Company, Limited (Bélgica c. España) (segunda fase), fallo, I.C.J. Reports 1970, pág. 32, párr. 33). La Corte considera que, si bien corresponde a la Asamblea General pronunciarse sobre las modalidades necesarias para garantizar la conclusión del proceso de descolonización de Mauricio, todos los Estados Miembros deben cooperar con las Naciones Unidas para poner en práctica esas modalidades. Como se recuerda en la Declaración sobre los Principios de Derecho Internacional referentes a las Relaciones de Amistad y a la Cooperación entre los Estados de conformidad con la Carta de las Naciones Unidas:

“Todo Estado tiene el deber de promover, mediante acción conjunta o individual, la aplicación del principio de la igualdad de derechos y de la libre determinación de los pueblos, de conformidad con las disposiciones de la Carta, y de prestar asistencia a 
las Naciones Unidas en el cumplimiento de las obligaciones que se le encomiendan por la Carta respecto de la aplicación de dicho principio" (resolución 2625 (XXV) de la Asamblea General).

181. En lo que respecta al reasentamiento en el archipiélago de Chagos de los nacionales de Mauricio, en particular los originarios del archipiélago de Cha gos, se trata de una cuestión relativa a la protección de los derechos humanos de los afectados que la Asamblea General debería abordar durante la conclusión del proceso de descolonización de Mauricio.

182. En respuesta a la cuestión b) de la Asamblea General, relativa a las consecuencias en virtud del derecho internacional que se derivan de que el Reino Unido siga administrando el archipiélago de Chagos, la Corte concluye que el Reino Unido tiene la obligación de poner fin a su administración del archipiélago d e Chagos con la mayor rapidez posible y que todos los Estados Miembros deben cooperar con las Naciones Unidas a fin de completar el proceso de descolonización de Mauricio.

183. Por las razones que anteceden, LA CORTE,

1) Por unanimidad,

Declara que tiene competencia para emitir la opinión consultiva solicitada;

2) Por 12 votos contra 2 ,

Decide responder a la solicitud de opinión consultiva;

A FAVOR: Presidente Yusuf; Vicepresidenta Xue; Magistrados Abraham, Bennouna, Cançado Trindade, Gaja, Sebutinde, Bhandari, Robinson, Gevorgian, Salam, Iwasawa;

EN CONTRA: Magistrados Tomka, Donoghue;

3) Por 13 votos contra 1 ,

Opina que, teniendo en cuenta el derecho internacional, el proceso de descolonización de Mauricio no se completó con arreglo a derecho cuando dicho país accedió a la independencia en 1968, después de la separación del archipiélago de Chagos; 
A FAVOR: Presidente Yusuf; Vicepresidenta Xue; Magistrados Tomka, Abraham, Bennouna, Cançado Trindade, Gaja, Sebutinde, Bhandari, Robinson, Gevorgian, Salam, Iwasawa;

EN CONTRA: Magistrada Donoghue;

4) Por 13 votos contra 1 ,

Opina que el Reino Unido tiene la obligación de poner fin a su administración del archipiélago de Chagos con la mayor rapidez posible;

A FAVOR: Presidente Yusuf; Vicepresidenta Xue; Magistrados Tomka, Abraham, Bennouna, Cançado Trindade, Gaja, Sebutinde, Bhandari, Robinson, Gevorgian, Salam, Iwasawa;

EN CONTRA: Magistrada Donoghue;

5) Por 13 votos contra 1 ,

Opina que todos los Estados Miembros tienen la obligación de cooperar con las Naciones Unidas a fin de completar el proceso de descolonización de Mauricio.

A FAVOR: Presidente Yusuf; Vicepresidenta Xue; Magistrados Tomka, Abraham, Bennouna, Cançado Trindade, Gaja, Sebutinde, Bhandari, Robinson, Gevorgian, Salam, Iwasawa;

EN CONTRA: Magistrada Donoghue.

Hecho en francés y en inglés, siendo la francesa la versión auténtica, en el Palacio de la Paz (La Haya), el día veinticinco de febrero de dos mil diecinueve, en dos ejemplares, uno de los cuales se depositará en los archivos de la Corte y el otro se transmitirá al Secretario General de las Naciones Unidas.

(Firmado) Abdulqawi Ahmed Yusuf,

Presidente

(Firmado) Philippe Couvreur,

Secretario

La Vicepresidenta Xue adjunta una declaración a la opinión consultiva de la Corte; los Magistrados Tomka y Abraham adjuntan sendas declaraciones a la opinión consultiva de la Corte; el Magistrado Cançado 
Trindade adjunta una opinión separada a la opinión consultiva de la Corte; los Magistrados Cançado Trindade y Robinson adjuntan una declaración conjunta a la opinión consultiva de la Corte; la Magistrada Donoghue adjunta una opinión disidente a la opinión consultiva de la Corte; los Magistrados Gaja, Sebutinde y Robinson adjuntan sendas opiniones separadas a la opinión consultiva de la Corte; los Magistrados Gevorgian, Salam e Iwasawa adjuntan sendas declaraciones a la opinión consultiva de la Corte.

(Rubricado) A. A. Y.

(Rubricado) Ph. C. 